\title{
CASE STUDY OF CHILD, PARENT, AND TEACHER PERCEPTIONS OF A SCHOOL-BASED HEALTH CLINIC IN THE MODEL SCHOOLS PAEDIATRIC HEALTH INITIATIVE OF THE TORONTO DISTRICT SCHOOL BOARD
}

\author{
by \\ Jacqueline H. Chan \\ Honours Bachelor of Arts in Psychology, York University, Toronto, 2014 \\ A Major Research Paper \\ Presented to Ryerson University \\ in partial fulfillment of the requirements for the degree of \\ Master of Arts in \\ the Program of \\ Early Childhood Studies
}

Toronto, Ontario, Canada, 2015

(C) Jacqueline H. Chan 2015 


\section{Author's Declaration}

I hereby declare that I am the sole author of this major research paper.

I authorize Ryerson University to lend this major research paper to other institutions or individuals for the purpose of scholarly research.

I further authorize Ryerson University to reproduce this major research paper by photocopying or by other means, in total or in part, at the request of other institutions or individuals for the purpose of scholarly research.

I understand that my MRP may be made electronically available to the public. 


\title{
CASE STUDY OF CHILD, PARENT, AND TEACHER PERCEPTIONS OF A SCHOOL-BASED HEALTH CLINIC IN THE MODEL SCHOOLS PAEDIATRIC HEALTH INITIATIVE OF THE TORONTO DISTRICT SCHOOL BOARD
}

\author{
(C) Jacqueline H. Chan 2015 \\ Master of Arts \\ Early Childhood Studies \\ Ryerson University
}

\begin{abstract}
The purpose of this study is to investigate child, parent, and teacher perspectives of the role of a Toronto school-based health clinic (SBHC) in health care provision, as well as their experiences of accessibility, and comfort in use. This qualitative case study of a SBHC in the Toronto District School Board's Model Schools Paediatric Health Initiative (MSPHI) uses thematic secondary data analyses informed by a grounded theory approach. The results of this study provide evidence that the SBHC plays a key role in the provision of physical health care for children; reduces health-related school absences; addresses OHIP-related barriers; and enhances the coordination of health care services. Children's experiences of comfort over time remained stable; however, children's perceptions of accessibility improved over time which aligned with their increased SBHC utilization.
\end{abstract}

Key terms: children, health services, school-based health clinic, Model Schools Paediatric Health Initiative 


\section{ACKNOWLEDGEMENTS}

First and foremost, I wish to express my sincere appreciation to my supervisor, Dr. Sejal Patel, for giving me the opportunity to participate in this research and supporting my growth this past year. Thank you for your patient guidance, believing in my capabilities, and generosity of time throughout this entire process. I feel very privileged to have been under your supervision and I am very thankful for your dedication.

I would like to extend my genuine gratitude to Dr. Elizabeth McCay for offering her time, insight, and expertise as my second reader. Furthermore, I wish to thank Dr. Rachel Langford, the director of the School of Early Childhood Studies, for her gracious support as my committee chair. I am very honoured to have leading researchers and professionals in the fields of nursing and early childhood studies read my work.

This study was made possible by research grants awarded to Dr. Sejal Patel from the Faculty of Community Services at Ryerson University and the Toronto District School Board to investigate the Model Schools for Inner Cities Paediatric Health Initiative. I am also grateful to the students, families, and teachers who participated in this study.

My sincere thanks also go to the faculty at the School of Early Childhood Studies, Dr. Marni Binder as well as Dr. Natalya Androsova. Thank you for teaching me each in your own ways, supporting my intellectual growth, and contributing to my rewarding graduate journey.

To my dear friends as well as my classmates of the Masters of Arts in Early Childhood Studies cohort, thank you for being sources of laughter and joy, and for sharing in my successes and challenges. I am so thankful for your encouragements and faith in my capabilities. Most of all, I would like to thank my family and siblings for supporting in me in my pursuits. Thank you, Uncle Dave for your timeless words of wisdom. Last but not least, I am especially thankful to my mother for her unconditional love, guiding me as a person and encouraging me to follow my aspirations. 


\section{TABLE OF CONTENTS}

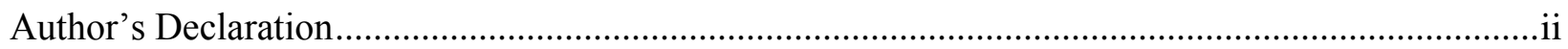

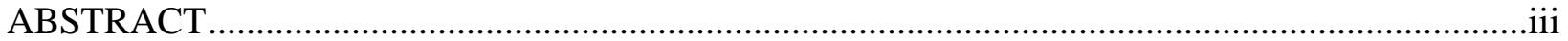

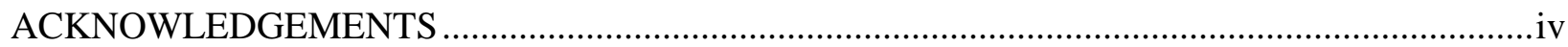

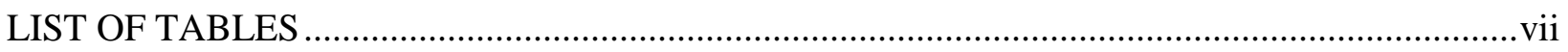

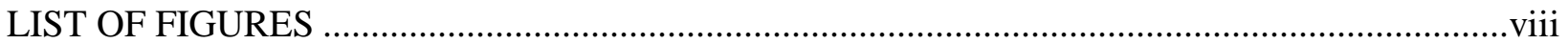

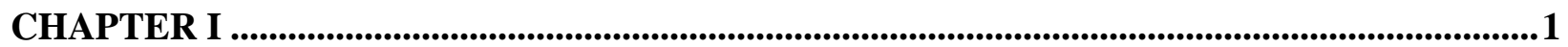

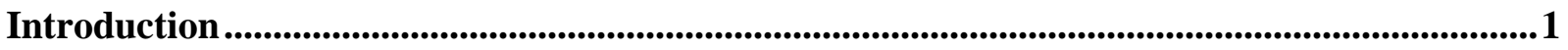

Canadian Health Care System and Eligibility of Health Insurance .......................................... 1

School-Based Health Clinic Model ..................................................................................... 4

Accessibility and utilization of school-based health clinics. ...................................6

Sustainability of school-based health clinics. ..................................................... 7

Educational climate and school-based health clinics.......................................... 8

Overall health status and school-based health clinics............................................. 9

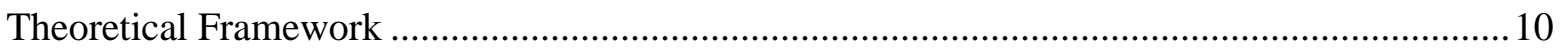

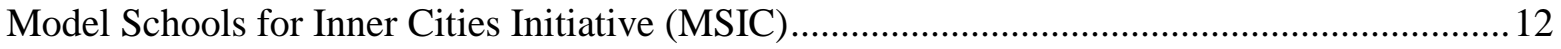

Model Schools Paediatric Health Initiative (MSPHI) ........................................................... 13

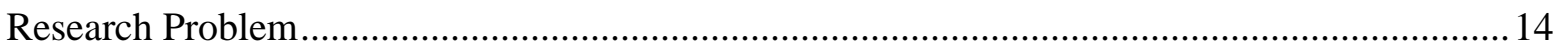

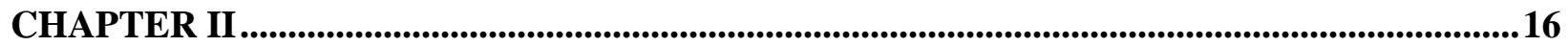

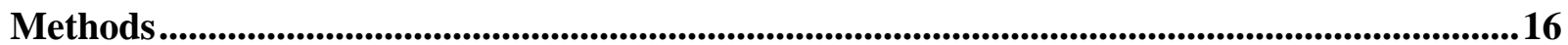

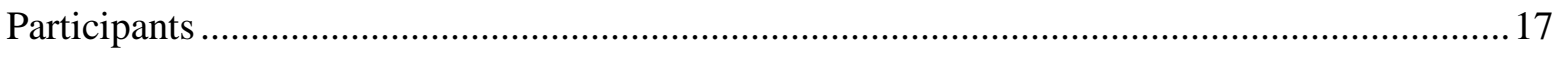

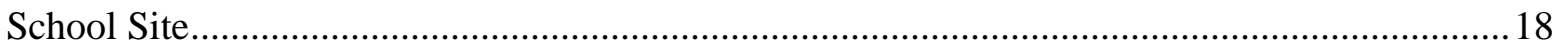

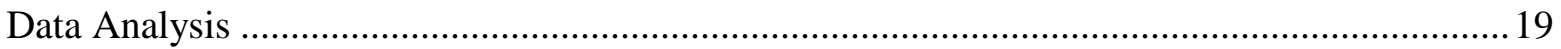

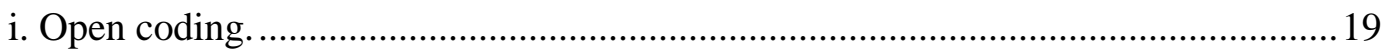

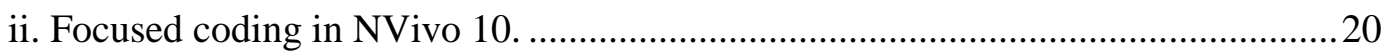

iii. Written summaries of focused codes............................................................. 20

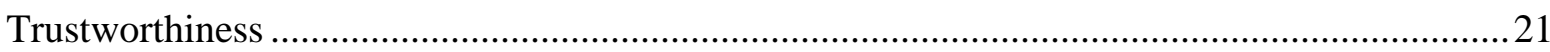

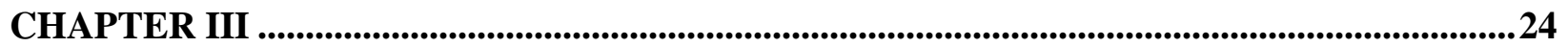

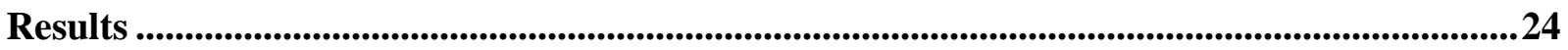


Question one: What are children's, parents' and teachers' perceptions of the role of the schoolbased health clinic in providing health care?

a) Physical health services and reduced health-related school absences. ...................25

b) Mental health services at the school-based health clinic......................................26

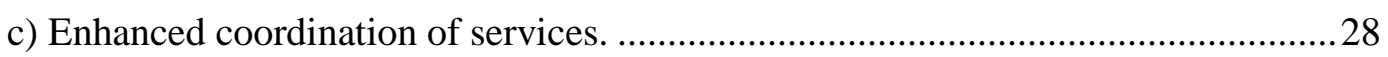

Question two: What are children's, parents' and teachers' perceptions of their access to the school-based health clinic?

a) OHIP-related barriers to accessibility.

b) Hours of service and accessing information at school-based health clinic. 30

Question two, part (b): Are there changes in children's perceptions of their access to the schoolbased health clinic over time?

a) Comfort related to the sense of community. 33

b) Comfort related to the school-based health clinic staff. 34

Summary of Findings .35

CHAPTER IV .37

Discussion. .37

Question one: What are children's, parents' and teachers' perceptions of the role of the schoolbased health clinic in providing health care?

a) Physical health services and reduced health-related school absences. 37

Question two: What are children's, parents' and teachers' perceptions of their access to the school-based health clinic?

a) OHIP-related barriers to accessibility.

b) Hours of service and accessing information about the school-based health clinic. 42 Question two, part (b): Are there changes in children's perceptions about their access to the school-based health clinic over time?

Question three: What are children's, parents' and teachers' experiences of comfort (or discomfort) in accessing the school-based health clinic?

a) Comfort related to the sense of community and SBHC staff.

Question three, part (b): Are there changes in children's perceptions of the school-based health clinic as a comfort (or uncomfortable) place over time? .45

Limitations of the Study 46

Conclusion.

References 


\section{LIST OF TABLES}

TABLE 1. FoCUS GROUP TRANSCRIPTS ANALYZED ............................................................. 17 


\section{LIST OF FIGURES}

FigURE 1. DiAGRAM OF BRONFENBRENNER's ECOLOGICAL SYSTEMS THEORY (1986)................... 10

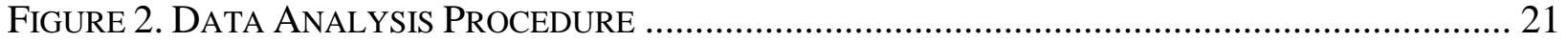




\section{CHAPTER I}

\section{Introduction}

In seeking ways to better support children's access to health care, models of school-based health clinics (SBHC) have been investigated by researchers internationally (e.g., Allen, MeadowsOliver, Ryan-Krause, 2008; Capella, Frazier, Atkins, Schoenwald, \& Glisson, 2008; Freeman et al., 2013; Wenzel, 1996), and among different populations, such as families facing homelessness (Berti, Zylbert, \& Rolnitzky, 2001); newcomer families (Yau \& Newton, 2012), and families living in poverty (Johnson \& Hutcherson, 2006). There is evidence that SBHCs improve access for children and families facing complex barriers to obtaining main stream health care (Baquiran, Webber \& Appel, 2002; Carpenter \& Mueller, 2001; Scudder, Papa, \& Brey, 2007; Wade et al., 2008; Yau \& Newton, 2012). This study examines a SBHC in Toronto which requires contextual information of the Canadian health care system and the relationship between immigration status and its bearing on health care access.

\section{Canadian Health Care System and Eligibility of Health Insurance}

A review of the Canadian health care system is necessary to understand the provision and accessibility of health care services at SBHCs. The health care system in Canada uses a mix of publicly and privately funded health insurance plans (Madore \& Tiedemann, 2005). Public health insurance is funded through government taxation and private health insurance is funded by individual payments in the form of insurance premiums that pool into a plan offered by non-government entities (e.g., insurance plans offered by employers) (Madore \& Tiedemann, 2005). In Ontario, primary and secondary medical care services are covered by the Ontario Health Insurance Plan (OHIP). Primary care services may be offered by physicians, who are also known as primary care providers. Primary care services include preventative care and treatment of common illnesses, 
injuries, and basic emergency services (Health Canada, 2012). Secondary care includes a range of specialized medical services such as acute emergency care, rehabilitation services, counselling, palliative care, and diagnostic testing that are predominately offered through hospitals and medical centres (Health Canada, 2012). Medical services not covered by OHIP include dental and vision care, medical equipment, prescription drugs, and long-term care for senior citizens or those with disabilities (Ontario Heath Insurance Act, 1990). Out-of-pocket medical expenses occur when individuals must cover the complete or a portion of the cost of medical services that are not covered by health insurance (Ontario Health Insurance Act, 1990). All provincial residents are covered by a public health insurance for primary and secondary care services as a stipulation of the Canada Health Act (1984) (Madore \& Tiedemann, 2005).

The Canada Health Act (1984) establishes five criteria for health care including: 1. Publicly administered in a not-for-profit basis (e.g., OHIP); 2. Comprehensive (e.g., covers medically required services); 3. Universal (e.g., for all residents and eligible individuals); 4. Portable (e.g., coverage while being temporarily absent from the province); and 5. Accessible (e.g., free of financial barriers) (Health Canada, 2014; Madmore \& Tiedemann, 2005). Most physicians are independent and private practitioners who utilize a fee-for-service model where fees are established by provinces and services are billed to the provincial public health insurance plan (Madore \& Tiedemann, 2005). The public health insurance system in Canada assures that access to services is based on need and not the ability to pay (Madore \& Tiedemann, 2005).

One essential principle outlined in the Canada Health Act (1984) is universality where all “insured persons" are entitled to the benefits of provincially sponsored health insurance plans (Health Canada, 2014). Insured persons are residents of a province with the "exception of specific groups" and those who have not completed the minimum three-month residency requirement (Health Canada, 2014). In 2007, there were 16,794 accepted refugee claimants and 27,912 refugee claims being processed for consideration (Citizenship and Immigration Canada, 2007 as cited in Elgersma, 2008). 
In-country claims are approved or rejected within three days of an individual's arrival to Canada (Elgersma, 2008). However, rejected claimants, may remain as temporary residents if the home country faces insecurity (Elgersma, 2008). Temporary residents are not entitled to the provincial health insurance plan (Elgersma, 2008; Ontario Health Insurance Plan, 1990); however, the government of Ontario has recently implemented a new health program in 2014 to serve refugee claimants (Ministry of Health and Long-Term Care, 2013) though its long-term stability in light of policy changes has yet to be established. Once status is conferred, however, the individual and other eligible individuals under regulation 552 can be exempted from the minimum three-month residency requirement to receive an OHIP card (Ontario Health Insurance Act, 1990). Other ineligible individuals include those who have resided outside of Ontario for more than 212 days in any given calendar year (Ontario Health Insurance Act, 1990). The exclusion of certain groups for health insurance in Ontario is an impediment to universal and accessible health care in Canada.

School-based health clinics represent an important collaborative innovation that aims to provide physical and mental health services for children and youth who face multiple barriers to access including the lack of health insurance coverage or the inability to pay for care (Baquiran et al., 2002; Carpenter \& Mueller, 2001; Wade et al., 2008; Yau \& Newton, 2012). The key features that distinguish SBHCs are: 1. the unique the school access point; 2. reduced socio-demographic barriers that affect access (e.g., insurance coverage, socio-economic status, cultural background); and 3. a nurse-practitioner or collaborative service delivery model. These are common elements that are seen across various models of elementary, middle, and high school SBHCs in the United States and Canada (Freeman et al., 2013; Strozer, Juszczak, \& Ammerman, 2010; Yau \& Newton, 2012).

The National Assembly on School-Based Health Care (NASBHC) in the United States has the following mission statement: "Access to culturally competent, high quality, first-contact primary care through school-based health centres is an effective way to reduce health inequities and therefore, improve health outcomes for socially disadvantaged children and adolescents" (Strozer et al., 2010, 
p. 1). The NASBHC profiles the unique demographics and services of all existing SBHCs in the United States and the 2010 national census in the United States reported 1,909 recorded SBHCs, and 878 of which have on-site mental health services as well (Strozer et al., 2010). In Canada, SBHCsare fewer in number and there are six SBHCs in Toronto, Ontario (Yau \& De Jesus, 2014).

\section{School-Based Health Clinic Model}

School-based health clinics serve children of all ages in a wide range of locations such as in inner city neighbourhoods (Freeman et al., 2013; Silberberg \& Cantor, 2008), in elementary schools (Baquiran et al., 2002; Wade, Mansour, Line, Huentelman, \& Keller, 2008), as well as in middle schools and high schools (McNall, Lichty, \& Mavis, 2010). School-based health clinics represent an interdisciplinary approach to comprehensive physical and mental health services including checkups, vision and hearing screenings, health information, immunizations, treatment of acute illnesses (Strozer et al., 2010); and have expanded to provide on-site mental health and referral services including counselling, assessment and support for children's psycho-social development (Gall, Pagano, Desmond, Perrin, \& Murphy, 2009; Gou, Wade, \& Keller, 2008). A number of SBHCs have professional collaborations with a consulting community or hospital that deploys a paediatrician and/or family physician (Baquiran et al., 2002; Wade et al., 2008). Although some SBHCs have expanded their scope to include dental services (Johnson \& Hutcherson, 2006) or with the increased availability of an on-site psychologist or school counsellor (Wade et al., 2008), the common thread amongst most SBHCs was an on-site school nurse practitioner.

The history of SBHCs in the United States dates back to 1902, when a school nurse was first hired by a public school to provide treatment for children who had contagious communicable diseases and were absent from school (Vessey \& McGowan, 2006). At the time, public schools in the United States had an attendance policy requiring ill students to remain at home (Keeton, Soleimanpour, \& Brindis, 2012). Currently, the school nurse practitioner is the primary source of 
comprehensive medical care for students in SBHCs (Strozer et al., 2010). The nurse practitioner model uses a collaborative approach to health care; with other health professionals (i.e., family physician, psychologist, and/or social worker) either in a collaborative multi-disciplinary team or as an extension for referrals services to specialists (Donald et al., 2010; Gould, Johnstone, \& Wasylkiw, 2007). In Canada, nurse practitioners have health care practices beyond the scope of registered nurses with educational accreditation to autonomously assess, treat, and administer medical care (Canadian Institute for Health Information [CIHI], 2010). This includes aspects of primary health care such as disease prevention, health promotion, and providing referrals to specialists (Canadian Institute for Health Information [CIHI], 2010). A majority of nurse practitioners in Canada in 2004-2005 provided health care to marginalized populations (e.g., those who are recent immigrants, unemployed, low-income earners), and over $50 \%$ of nurse practitioners reported working in under serviced locations (Van Soeren, Hurlock-Chorostecki, Goodwin, \& Baker 2009).

School-based health clinics have an underlying premise that schools are "an innovative access point for children facing healthcare barriers to receive needed services in the most direct and efficient way" (Yau \& Newton, 2012, p. 1). Schools are in a key position to support children's physical, cognitive, socio-emotional and academic development (Atkins, Hoagwood, Kutash, \& Seidman, 2010) because children are at school every day for up to ten months every year. In Canada, an example of a school-based program that draws upon the concept of the school as a community hub for care and family support services is the Toronto First Duty project (TFD) (Patel \& Corter, 2011). Research on the TFD project has demonstrated an association between participation in school-based TFD programs/services and children's developmental outcomes (Patel, Corter, Pelletier, \& Bertrand, 2015) and improved parental self-efficacy in supporting their children's learning (Patel \& Corter, 2013). SBHCs in Canada use a similarly comprehensive approach to supporting children and families outside of the classroom. The existing infrastructure in schools (e.g., social and educational support and learning resources) makes it a strategic setting for SBHCs to improve community participation 
and improve students' opportunities to access health care (Atkins et al., 2010). While often offered in targeted communities, school-based health clinics are considered universal interventions which are broad-reaching initiatives with aims to be accessible to all members of the community regardless of socio-demographic and individual level risk factors (Durlak, Weissberg, Dymnicki, Schellinger, \& Taylor, 2011). In comparison to individual-level clinical interventions, the benefits of universal interventions include minimal stigmatization, improved public support, and an increased capacity to support communities through the universal platform from which services could be additionally targeted (Patel \& Corter, 2011). The literature suggests that the convenience of health care in a familiar school-based location encourages parents' and children's utilization of medical services when needed.

\section{Accessibility and utilization of school-based health clinics.}

Studies of the effectiveness of SBHCs dominate the literature, specifically qualitative case studies (Brown \& Bolen, 2008; Carpenter \& Mueller, 2001; Gall et al., 2009) and longitudinal studies (Baquiran et al., 2002; Johnson \& Hutcherson, 2006; Wade et al., 2008) that suggest that SBHCs impact access, health-seeking behaviour, and health outcomes among users. Canadian studies, including community reports, have shown that SBHCs reach inner city children (Freeman et al., 2013; Yau \& De Jesus, 2014; Yau \& Newton, 2012; Yau \& Newton, 2013). Case studies of specific schools show that SBHC users were more likely to belong to "marginalized" families who faced linguistic barriers, lack of insurance, lower-socioeconomic status, and stigmatization (Freeman et al., 2013; Yau \& De Jesus, 2014; Yau \& Newton, 2012; Yau \& Newton, 2013). These barriers to access, including difficulty accessing treatment, immunizations, examinations, and inadequate continuity of care are reported to affect children with health insurance as well (Baquiran et al., 2002; Freeman et al., 2013; Guo et al., 2005; Wade et al., 2008). In the United States, students without health insurance were more likely to use and be enrolled in a SBHC and to be referred for health 
needs (Wade et al., 2008). Of the1,700 SBHC visits seen over one school year, $78 \%$ of the children did not have health insurance (Carpenter \& Mueller, 2001); and in three SBHCs over half (53\%) of the 2795 student encounters were in the self-pay (i.e., no insurance) category (Baquiran et al., 2002). While children used the SBHC for short-term health needs such as immunizations, physical examinations, and superficial wounds, a large number of children accessing SBHCs suffer from chronic disease (Freeman et al., 2013; Guo et al., 2005; Johnson \& Hutcherson, 2006; Wade et al., 2008). Upper-respiratory disease, attention deficit hyperactivity disorder, and autism spectrum disorder were amongst some of the most frequently cited concerns seen at SBHCs (Baquiran et al., 2002; Freeman et al., 2013; Guo et al., 2005; Johnson \& Hutcherson, 2006). Moreover, children’s current health needs must be addressed not only in terms of current conditions, but also in terms of future implications for health (Brown \& Bolen, 2008). Adolescents, in particular, have a greater tendency toward engaging in risky health behaviours with adverse short and long-term consequences (Ali, Dwyer, Vanner, \& Lopez, 2010). While SBHCs are able to meet the physical health needs of many adolescents, a large number of young people are affected by socio-emotional and behavioural disorders (Gampetro, Wojciechowski, Elizabeth, \& Amer, 2012) which can be exacerbated by a greater number of adverse experiences and the experience of living in poverty (Daly, Ziegler, \& Goldstein, 2004). The SBHC represents a comprehensive range of preventative and early intervention services. Along with primary care, the SBHC is an important response to the growing health needs of children and adolescents who have access to limited resources (McNall et al., 2010).

\section{Sustainability of school-based health clinics.}

School-based health clinics are sometimes jointly operated by community medical centres and hospital sponsors (Strozer et al., 2010). The research literature on SBHCs show that they remove geographic, cultural, and economic barriers due to its innovative in-school location; however, a common underlying challenge is the sustainability of the SBHC model. They sometimes have 
unstable sources of funding that challenges its long-term stability of its broad-reaching initiative to provide a broad range of primary and preventative care services. Directly addressing questions related to sustainability and financing options is an important part of the community dialogue. To ensure that expenditures are maintained and services are of sufficient quality requires greater accountability, both in terms of health and education outcomes (Brindis et al, 2003). Expenditures relate to the support of services not related to direct-patient care include the development of programs, operations, staffing, clinical supervision, after-hours care, and medical back-up (Brindis et al., 2003). Research on SBHC utilization and accessibility contributes to the growing evidence of its effectiveness that researchers say will contribute to growing private and public financial support (Brindis et al., 2003). Partnerships between hospitals, schools, and partner agencies are important because partners can contribute a diverse range of expertise, resources, and creates sites for multidisciplinary training (Swider \& Valukas, 2004). The SBHC's ability to enhance educational climate adds to the literature on SBHC efficacy both in terms of health and educational outcomes (Strolin-Goltzman, Sisselman, Melekis, \& Auerbach, 2014).

\section{Educational climate and school-based health clinics.}

A number of studies have attempted to explore connections between educational outcomes and SBHC use. For instance, the presence of a SBHC at school has been associated with children's enhanced sense of school connectedness, suggesting that children develop a stronger sense of school bonding (e.g., feeling welcomed at school, liking school), school attachment (e.g., perceiving adults as supportive, respect for school health professionals), and commitment to educational goals (StrolinGoltzman et al., 2014). These factors are significantly associated with enhanced student engagement and improved academic performance (Klem \& Connell, 2009). These finding suggest that children perceive SBHC staff as caring individuals who have high expectations of their educational performance (Stone, Whitaker, Anyon, \& Shields, 2013). These factors likely contribute to an 
improved learning environment. This link is further supported by quantitative research that illustrated students' improved grades after SBHC use (Strolin-Goltzman et al., 2014). An additional study reported that SBHC use for physical health concerns (e.g., respiratory illness, immunizations) was associated with school attendance gains (Gall et al., 2000), while mental health services were strongly related to GPA gains (Walker, Kerns, Lyon, Bruns, \& Cosgrove, 2010). Either way, these studies suggest that SBHCs can support schools in meeting their educational goals for students and they contribute to the growing evidence of the efficacy of SBHCs.

\section{Overall health status and school-based health clinics.}

School-based health clinics facilitated significantly improved medical access and coverage for children who were homeless (Berti et al., 2001). One study reported the reduced risk of hospitalization and emergency department visits for children who had an integrated SBHC in comparison to schools without SBHCs (Guo et al., 2005). The literature shows that SBHCs have a positive effect on children's well-being over time on physical health-related quality of life (HRQOL) (Guo et al., 2008) and psycho-social HRQOL (Wade et al., 2008). Two longitudinal studies suggest that there are short- and long-term benefits including learning, cognitive and physical development (Guo et al., 2008; Wade et al., 2008). When individual-level factors such as insurance coverage, income, family status, and chronic condition type (e.g., learning disabilities, asthma, attention-deficit disorder) were accounted for in the study, children with chronic health conditions still had increased HRQOL ratings after SBHC use, to match those of non-SBHC users (Wade et al., 2008). The efficacy of SBHC mental health services shows promise. A large-scale meta-analysis of school-based universal interventions found that students had significantly improved socio-emotional skills (e.g., social skills and conflict resolution), improved attitudes toward the self and others (e.g., self-esteem and self-concept), positive social behaviour, academic performance, and reduced emotional distress and conduct problems post-intervention (Durlak et al., 2011). The literature shows that SBHCs aim 
to create an ecology of coordinated health services that break down barriers to access for underserved families and children.

\section{Theoretical Framework}

The current case study draws upon Bronfenbrenner's (1986) ecological systems theory. The ecological systems theory proposes that individuals' development are influenced by their environment. A defining property of this theory is its "nested arrangement of concentric structures, each contained within the next", with systems that are referred to as the micro-, meso-, exo-, macro-, and chronosystems (refer to Figure 1) (Bronfenbrenner, 1979, p. 21).

Figure 1. Bronfenbrenner's Ecological Systems Theory (1986)

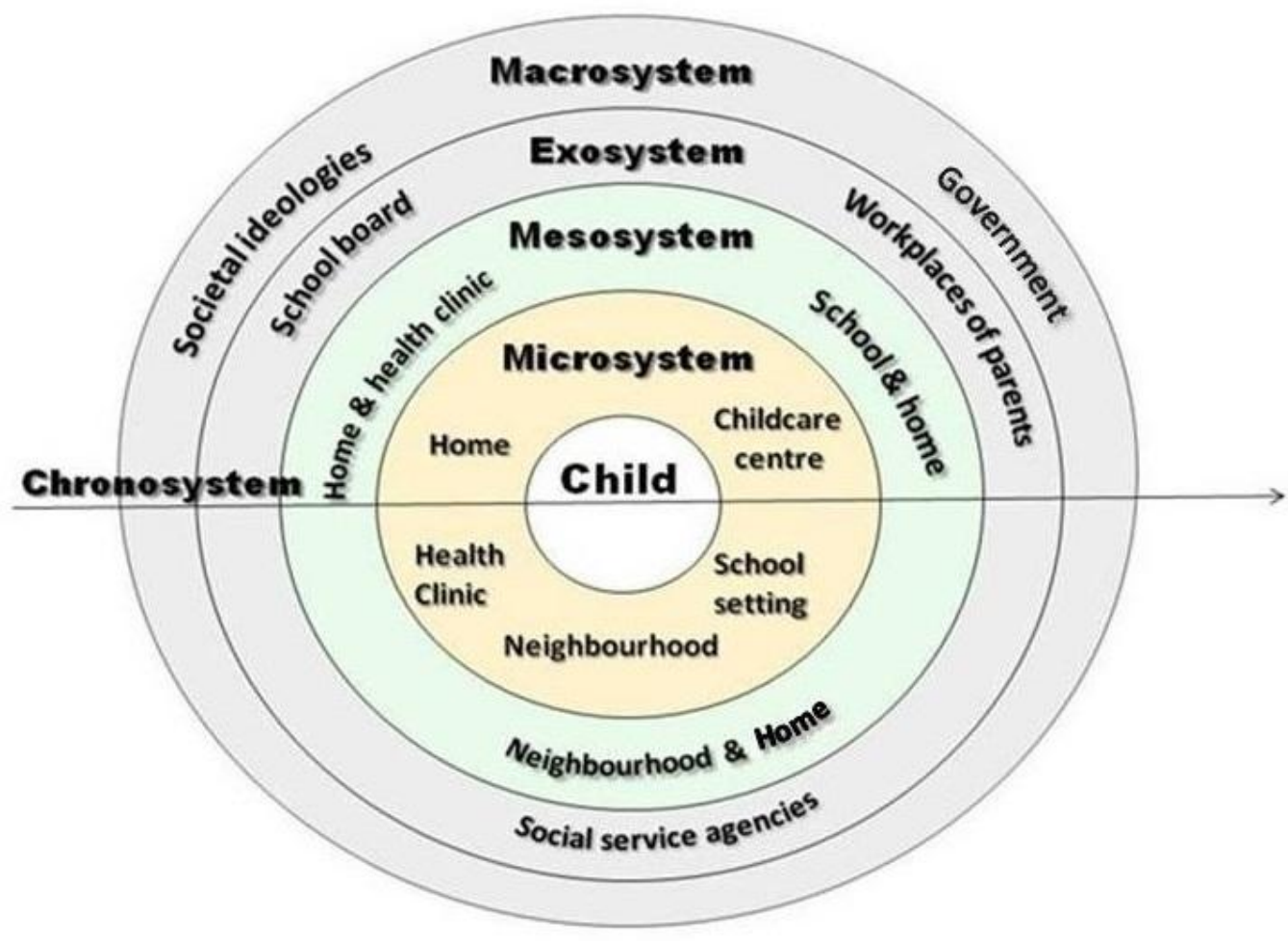

The developing child is at the center of the ecological system and is regarded as a dynamic and active individual who moves into the different systems and shapes the environment, while the environment is also influenced by the larger external systems (Bronfenbrenner, 1979). The 
microsystem is the immediate setting of the child, which is characterized by learning, social interactions, and activities (Bronfenbrenner, 1979). The mesosystem is characterized by interactions between the microsystems such as "the relations among home, school, and neighbourhood...It is formed or extended whenever the developing person moves into a new setting" (Bronfenbrenner, 1979, p. 25) (e.g., home and school connections). The exosystem includes settings that "do not involve the developing person as an active participant" (Bronfenbrenner, 1979, p. 25); however, has indirect affects the developing individual (e.g., decisions made by the school board). The macrosystem refers to the culture or subculture within a nation that exert influences by the means of socioeconomic or political atmosphere within any given society (Bronfenbrenner, 1979). The chronosystem refers to the changes and events that occur over time (Bronfenbrenner, 1986).

The SBHC interventions can be thought to enhance the coordination of services by supporting interactions between the microsystems of the home, school (including clinic personnel, school staff), and other primary care giving settings. Exosystem influences include decisions made by community partners of the SBHC, the municipal government, and the school board, which affect teachers' training, SBHC resources, and referral services. The macrosystem influences include the public attitudes toward SBHCs and the Canadian context of health care. The chronosystem refers to changes over time in the SBHC.

The ecology of human development theory has been applied to school, clinical and community prevention and intervention services (Atkins et al., 2010; Patel \& Corter, 2011). This theory has been effectively used to frame health promotion programs in schools (e.g., Townsend \& Foster, 2011) and early childhood programs (Patel \& Corter, 2011). The SBHC is co-located within the existing contexts that children spend their time in and uses the administrative, social, and educational infrastructure in an education system as a framework for providing medical care (Keeton, Soleimanpour, \& Brindis, 2012). The ecology of human development is a promising framework for 
school-based interventions due to its multilevel approach to understanding the external factors that influence child development (Atkins et al., 2010).

\section{Model Schools for Inner Cities Initiative (MSIC)}

The school-based health clinic being investigated in the current study falls under the mandate of the Model Schools for Inner Cities Initiative (MSIC), a Toronto District School Board (TDSB) initiative. The MSIC aims to provide students with equitable opportunities to access resources and tools to be fully engaged in their education and community (Yau \& Branco, 2012). The MSIC initiative includes the Model Schools Paediatric Health Initiative (MSPHI) which implements a SBHC in schools to address disparities in health care access (Yau \& Newton, 2012). The MSIC aims to enable all students to succeed academically and socio-emotionally regardless of socio-economic background (TDSB, 2005). There are five essential components that guide the initiative: 1. Innovative teaching practice, learning, and school structure (e.g., professional development initiatives for educators); 2. School services that support students' physical and socio-emotional well-being (e.g., partnering with Toronto Public health, providing access to a psychologist and SBHC services); 3. School as the heart of the community (e.g., community outreach and providing international languages programs for parents); 4. Research, renewal and evaluation process for continual school improvement and assessment of long-term impact (e.g., formative feedback for school staff and summative assessment); and 5. Commitment to share innovative practices and initiatives throughout the MSIC schools and TDSB (TDSB, 2005). The MSIC initiative is in neighbourhoods with dense poverty within Toronto and selected according to criteria (TDSB, 2005). Services and programs offered at MSIC schools demonstrate continued evidence of effectiveness in helping students achieve learning and health outcomes (Yau \& Newton, 2012; Yau \& Newton, 2013). Between 2010 and 2011, the MSIC served over 100 inner city schools, 85\% of the parents were born outside of Canada, and nearly half of the families were a part of the low-income bracket with an income of less than 
$\$ 30,000$ per year (Yau \& Newton, 2012). The MSIC identified a higher prevalence of undetected visual and/or auditory problems among students and barriers to obtaining needed medical care (Yau \& Newton, 2012).

\section{Model Schools Paediatric Health Initiative (MSPHI)}

The Model Schools Paediatric Health Initiative (MSPHI) provides comprehensive schoolbased health programs that support the second essential component of the MSIC, which is to support children's physical and socio-emotional well-being (TDSB, 2005). The MSPHI establishes SBHCs within elementary and high schools, with the aim to improve access to health care for students (Yau \& Newton, 2012). School-based health clinics "all shared the common goal of increasing access to comprehensive health care for marginalized student populations who faced barriers and challenges that prevented them from receiving proper health care, which in turn affected their education outcome.” (Yau \& Newton, 2012, p. 9). The MSPHI recognizes schools as an innovative access point for health services and delivers care through a three-way partnership: 1. Toronto Foundation for Student Success (i.e., funding, fundraising, program management); 2. MSIC (i.e., space for the SBHC, liaises with students, parents and healthcare providers, evaluates MSPHI); and 3. Delivery partners (i.e., professionals providing medical services) (Yau \& Newton, 2012). The overall aim of the MSPHI SBHC is to offer preventative care, health promotion, early detection and assessment of physical and mental health (Yau \& Newton, 2012). Additional SBHCs were created after funding was secured and subsequently, six SBHCs have been established in Toronto (Yau \& Newton, 2013). Currently, there are five elementary schools and one high school with a SBHC that are part of the TDSB (Yau \& Newton, 2014). MSIC research has documented a need for more Canadian studies to understand the overall state of SBHCs in Canada. The current study will contribute to the Canadian literature. 


\section{Research Problem}

The literature demonstrates that the provision of physical and mental health care in SBHCs has a history in the United States and has been under examined within a Canadian context. The recent development of SBHCs in the TDSB points to an opportunity for research to evaluate the shaping forces of families' experiences that influence their perceptions of accessibility to these programs. The present research uses a qualitative case study approach to gain an in-depth descriptive understanding of the SBHC and challenges faced by families that cannot be fully captured by statistical measures and includes children's voices. Given the research literature illustrating the efficacy of the SBHCs in enhancing school connectedness (Strolin-Goltzman et al., 2014); improving perceptions of access to caring adults (Stone et al., 2013); the use of a nurse practitioner model of care (Gould et al., 2007); improving children's self-reported health-related quality of life (Wade et al., 2008); and most importantly, improving accessibility for under serviced families through its school location (Freeman et al., 2013; Walker et al., 2010), the creation of a SBHC within the context of the Canadian health care system warrants deeper investigation.

The purpose of this study is to investigate child, parent, and teacher perceptions of the role of a MSPHI SBHC in the provision of health care, perceptions of accessibility and comfort, as well as changes in children's experiences of accessibility and comfort over time. This research uses a secondary analysis of qualitative data that were collected for a larger community partnered study led by Dr. Sejal Patel in partnership with the TDSB. The research questions that guide the current study are:

1. What are children's, parents' and teachers' perceptions of the role of the school-based health clinic in providing health care for children and families?

2. What are children's, parents' and teachers' perceptions of their access to the school-based health clinic? 
b. Are there changes in children's perceptions of their access to the school-based health clinic over time?

3. What are children's, parents' and teachers' experiences of comfort (or discomfort) in accessing the school-based health clinic?

b. Are there changes in children's perceptions of the school-based health clinic as a comfortable (or uncomfortable) place over time? 


\section{CHAPTER II}

\section{Methods}

The present study uses a secondary analysis of qualitative case study data to investigate child, parent and school staff perspectives of the role, accessibility, and comfort of accessing the MSPHI SBHC. This study used a thematic analysis informed by a grounded theory approach (Charmaz, 2006) to analyze primary data from one school site. Qualitative case studies provide an in-depth understanding of participants' perceptions and experiences and "allows in-depth, multi-faceted explorations of complex issues in their real-life settings" (Crowe et al., 2011, p. 1). The primary datasets used in this study were collected for a larger community-partnered umbrella project (Dr. Sejal Patel, principal investigator) and comprises of data collected from ten focus groups that took place at one school site (see Table 1 below). Data provided for the current study were already transcribed verbatim based on audio recordings, and field notes taken by research assistants who participated in the data collection were also provided for review. An extensive peer debriefing process took place with the principal investigator during the process of analysis to ensure trustworthiness of the research. Ethics approval from the Research Ethics Board at Ryerson University and the External Research Review Committee of the TDSB were obtained by the principal investigator.

There were six child focus group transcripts collected over time (i.e., 2011, 2012, and 2015). Child focus group data were not collected in 2013 and 2014 at the focal school site. There were an average of 6 children in each child focus group, and 9 adults in each parent focus group, and there was one teacher focus group with 8 participants. The children, parents, and teachers were asked about their experiences using the SBHC, amongst other topics related to their experiences with the focal school (e.g., school programs, school built environment, and perceptions of safety). 
Table 1. Focus Group Transcripts Analyzed

\begin{tabular}{cccc}
\hline & 2011 & 2012 & 2015 \\
\hline $\begin{array}{c}\text { JK }-\begin{array}{l}\text { Gr. 2 Focus } \\
\text { Group }\end{array} \\
\text { Gr. } 3 \text { - Gr. 5 Focus } \\
\quad \text { Group }\end{array}$ & 1 & 1 & 1 \\
Parent Focus Group & 0 & 1 & 1 \\
Teacher Focus Group & 0 & 0 & 3 \\
\hline
\end{tabular}

\section{Participants}

Child focus groups with a total of 33 children were split developmentally with groups including students in Junior Kindergarten to Grade 2 and Grade 3 to Grade 5, carried out at three time points. There were additionally three parent focus groups carried out with a total of 27 parents at one time point, and one teacher focus group with 8 participants. There were a total of 68 child, parent and teacher participants. Child and parent participants were culturally diverse and able to participate in conversational English. Focus groups were conducted in English. Children reported on how long they were at their current school. There appeared to be a shift in children's prior and current enrolment patterns; where it seemed that more children in 2015 reported experiencing greater school mobility prior to their attendance at the focal elementary school. Approximately two-thirds of parents reported a birthplace outside of Canada and two-thirds of children reported speaking a second language in addition to English. The teachers were predominantly female, with one male teacher participant. The teacher focus group included both permanent and occasional teachers of grades one to five. 


\section{School Site}

The focus groups were held at an elementary school in Toronto that is a considered a highpriority and inner city neighbourhood by the TBSB Learning Opportunities Index (LOI) (TDSB, 2014). Based on data collected by TDSB in 2011, sixty-five percent of the parents at this school were born outside of Canada (newcomers, including immigrants and refugees) and seventy-three percent of families belong to the low-income category (Yau \& Newton, 2012). The school was one of the original two SBHCs that opened between the years 2010-2011 (Yau \& Newton, 2012). The MSPHI SBHC serves students from within the focal school's catchment area and also from neighbouring school communities (Yau \& Newton, 2013). The SBHC at the focal school is open for appointments/referrals on Thursdays, and is operated in partnership with Access Alliance Multicultural Health Centre, Toronto East General Hospital and the Toronto Foundation for Student Success. The SBHC is staffed by a nurse practitioner, a paediatrician, an off-site consulting physician, and a clinic coordinator who is a multilingual international medical graduate (Yau \& Newton, 2012).

The elementary school has a student population of over 600, with students from Kindergarten to grade six; $63 \%$ of students speak another language other than English; $22 \%$ of students were born outside of Canada and have lived in Canada for five years or less; and nearly $10 \%$ of the students have lived in Canada for less than two years.

The school offers a settlement program for newcomer parents and adult English as a Second Language (ESL) programs for parents. Other programs provided at the school include nutrition programs, parenting workshops, and there is also a Parent and Family Learning Centre (PFLC) at the school for parents and caregivers with children from infancy to 6 years of age.

The TDSB developed the Learning Opportunity Index (LOI) to measure the number of poverty-related risk factors at the neighbourhood level that may affect children's learning (e.g., 
median income, adults with low education, and families receiving social assistance) (TDSB, 2014). The school under study received an LOI score of approximately 0.84 , denoting a high-priority community (TDSB, 2014). The LOI helps TDSB identify the allocation of resources to its more impoverished schools. The LOI score has a value of between 0 and 1 , where scores closer to 1 denote a higher number of external poverty-related risk factors that may impede student achievement (TDSB, 2014). The LOI is recalculated every two years (TDSB, 2014).

\section{Data Analysis}

A thematic analysis (Braun \& Clarke, 2006) informed by a grounded theory approach (Charmaz, 2006) was used to analyze the data. The study used an inductive and emergent approach and themes were data-driven and emerged from the transcripts. The process of emergent coding supersedes any attempts to conform the data to pre-existing coding structures and preconceptions (Braun \& Clarke, 2006). The data were analyzed using Microsoft Word and NVivo 10 applications. (i.e., 6 child transcripts, 3 parent transcripts, and 1 teacher transcript). The process of data analysis comprised of three main steps that outlined below (see Figure 2). The data were saved on a secure password protected Ryerson server.

\section{i. Open coding.}

Each transcript was converted to a Microsoft Word-compatible format and open coding was conducted in Microsoft Word. The aim of open coding is to remain open to all possible theoretical and thematic orientations of the data (Braun \& Clarke, 2006). The themes that emerged in the margins of the transcripts were noted using the annotation function (Braun \& Clarke, 2006). Annotations were given a corresponding number which served as an identification marker for lineby-line coding. Each annotation represented an open code. 
After each transcript was open coded, common and re-occurring codes were grouped together to form themes. There were approximately 2500 open codes that were organized into themes. The themes and sub-themes from each transcript were cross-checked to identify re-occurring and common themes across all three stakeholder groups (i.e., children, parents, and teachers), where applicable. This was the initial formulation of emerging themes and sub-themes and formed the basis of the Focused Coding Guide.

\section{ii. Focused coding in NVivo 10.}

A content coding manual (i.e., Focused Coding Guide) was created following the organization of themes from open coding. The Focused Coding Guide is a reduced compilation of open codes from the stakeholder transcripts. Coding involved a peer debriefing process, and the themes were reviewed, developed and discussed with the principal investigator.

The transcripts were focused coded line-by-line using NVivo 10, which is a qualitative data analysis software. The themes and sub-themes were entered into NVivo 10 as 'parent' nodes and 'child' nodes. There were 30 parent nodes, and 49 child nodes in the NVivo dataset. There were no additional new themes that emerged during the process of coding, and the data was found to fit into a either a parent nodes or a child node.

\section{iii. Written summaries of focused codes.}

After the data were coded in NVivo, the nodes were exported and data relevant to the research questions were summarized in detail, with salient quotes included, organized by theme. This process served as an additional coding verification step, with peer review debriefing with the principal investigator, and formed the basis of the results summary. The exported data were examined carefully for missing contexts to ensure that the researcher understood the questions asked and the context of the verbatim. 
Figure 2. Data Analysis Procedure

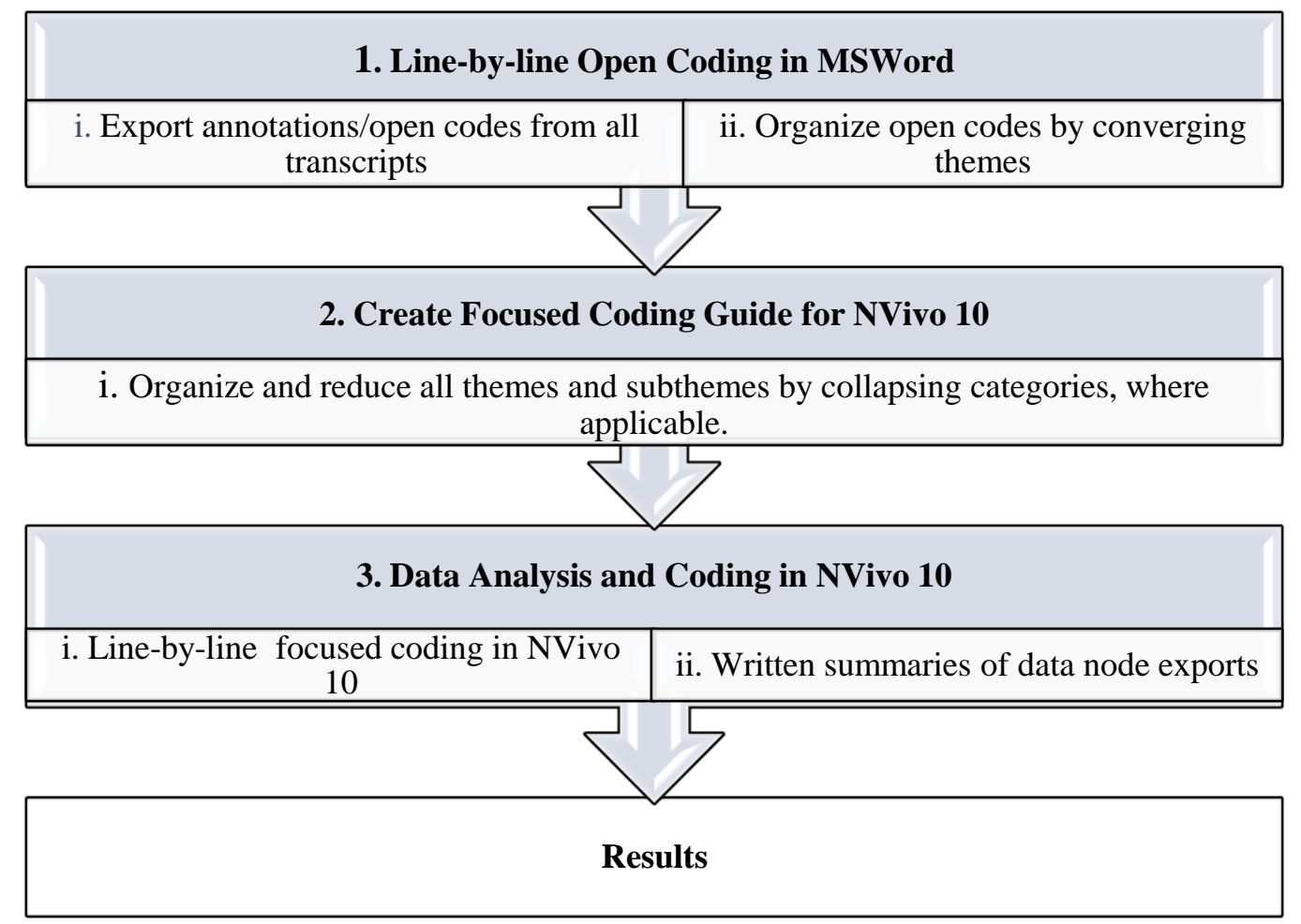

\section{Trustworthiness}

Trustworthiness refers to the validity of the study, demonstrated through the credibility, transferability, dependability and confirmability of the research (Shenton, 2004). Credibility refers to the quality of research that "measures or tests what is actually intended" (Shenton, 2004, p. 64). As this study used a secondary analysis of data collected for a larger umbrella project, the research methodology of the primary data determines the credibility of this study; however, the researcher sought to ensure credibility of the data analyses through an on-going peer briefing process with the principal investigator, Dr. Sejal Patel. Peer debriefing refers to participating in analytic discussion with colleagues for the purposes of exploring potential biases and recognizing potential flaws during data analysis (Lincoln \& Guba, 1985). The researcher participated in weekly meetings with the principal investigator and during these discussions, concepts derived from the data during the course 
of research were examined and feedback was thoroughly discussed to contribute to the trustworthiness of the current study.

Triangulation is a method to establish trustworthiness of the study by using multiple sources of information to assure consistency across data (Shenton, 2004). The sources of data used for triangulation were the use of researcher field notes, written immediately after each focus group and the use of detailed description notes which offered a detailed and accurate portrayal of the focus group settings (Shenton, 2004) as well as data collected from multiple stakeholder perspectives (i.e., children, parents, and teachers). Data adequacy is frequently premised upon theoretical saturation, which is denoted by the saturation of findings whereby no new additional themes emerge from the data that do not already fit within the existing coding scheme (Padgett, 1998). The data analyzed in the current study fit into the developed coding scheme outlined in the Focused Coding Guide..

Transferability refers to the applicability of the findings to another environment setting (e.g., whether the findings from the current study can be generalized to other inner city schools) (Shenton, 2004). The setting of the research site and description of the Canadian health care context is described to provide contextual information for this purpose. In addition, a detailed outline of the data analysis strategy provided for this study assists any researchers interested in replicating the findings or analytic strategy.

Dependability refers to the potential for similar findings to be replicated in the case that similar recruitment, data collection, and analysis were repeated with the same methods and participants (Shenton, 2004). The process of peer debriefing, triangulation of sources, and theoretical saturation contributes to the dependability and the trustworthiness of the research.

The confirmability of the study refers to the objectivity of the research inquiry that is not formed from the biases of the researcher (Shenton, 2004). The objectivity of the study was sought to be maintained through the use of direct quotes from the participants to accurately represent the findings. The subjective quality of focus group research data collection and data analysis may be 
informed by the research team's prior experiences and level of training (Fatemeh, 2004); however, the several aforementioned efforts that were carried out throughout the research analysis process contribute to the trustworthiness of the findings. 


\section{CHAPTER III}

\section{Results}

The aim of this study was to investigate child, parent, and teacher perceptions of accessing SBHC services at an inner city elementary school in Toronto, with particular interest in understanding the role of the SBHC in the delivery of health care, perceptions of accessibility and comfort in accessing the SBHC, as well changes in children's perceptions of accessibility and comfort over time. Several themes that emerged across the child, parent and teacher groups are identified in the following section, organized by research question. The following is an overview of the research questions and findings:

Question one: What are children's, parents' and teachers' perceptions of the role of the schoolbased health clinic in providing health care? The following themes emerged: (a) physical health services and reduced health-related school absences; (b) mental health services; and (c) enhanced coordination of services.

Question two: What are children's, parents' and teachers' perceptions of their access to the school-based health clinic? The findings comprise of the following themes: (a) OHIP-related barriers to accessibility; and (b) hours of service and accessing information at SBHC.

Question two, part (b): Are there changes in children's perceptions of their access to the school-based health clinic over time? The findings illustrate that there were changes over time in 2011, 2012, and 2015 in children's perceptions of access.

Question three: What are children's, parents' and teachers' experiences of comfort (or discomfort) in accessing the school-based health clinic? The findings include the following themes: (a) accessibility related to the sense of community at school; and (b) accessibility related to the SBHC staff. 
Question three, part (b): Are there changes in children's perceptions of school-based health clinic as a comfort (or uncomfortable) place over time? The findings illustrate that children's perceptions of the SBHC as a comfortable place were relatively stable over time from 2011, 2012, 2015.

\section{Question one: What are children's, parents' and teachers' perceptions of the role of the school-} based health clinic in providing health care?

The participants were asked about their perceptions of the role of the SBHC in providing health care services. The following themes emerged from the data: (a) physical health services and reduced health-related school absences; (b) mental health services; and (c) enhanced coordination of services.

\section{a) Physical health services and reduced health-related school absences.}

Children, parents and teachers had converging perceptions about the provision of physical health care at the SBHC. Parents spoke about using the SBHC for immunizations, bug bites, in addition to immediate critical care for playground incidents. One parent said,

And another thing is kids are just playing around and instantly anything can happen. That time I could be working is [in] some distance place, the school called me, you're scared. It is not possible to come immediately. So at the clinic they take the responsibility and take care of her. That's very good support for me especially.

In addition to the importance of the SBHC for first-aid, the SBHC offered referrals to communitylinked health agencies that provided services at a reduced or no-cost. One parent said, "Thanks to this clinic, though they don't treat dentistry, but they help people how to go, how to get treatment." The SBHC was also a trusted resource for health care information. For example, one parent said,

When I take my child to school there is a settlement worker, there is a clinic, it is a good place, 'how can I help you?' I need these things. He goes [and] he gave information to me, healthcare information, settlement information, and it is free. 
Children, parents and teachers use the SBHC for immunizations. A parent said, "All the time for vaccination. And only three times I have used." One teacher said that she referred approximately 10 children to the SBHC in the past year for vaccinations. Another teacher said, "Like we've said before, I've had kids go for shots and be back in class 10 minutes later where they would normally miss an entire day of school." Two-thirds of the parents used the SBHC for immunizations which helped their child stay in school and prevented immunization-related suspensions. A parent said,

It took six weeks just to get the birth registration forms so without the clinic here I would have had to wait two months before my son would start school. So he would have missed half of his JK.

The parent required the birth registration forms to apply for OHIP coverage to receive immunizations; however the SBHC was able to provide school-related immunizations for free for children without OHIP. Many teachers reported referring students to the SBHC for ear infections, fevers, vision and hearing check-ups, in addition to nutritional information. One teacher spoke about the positive effect of the SBHC on a child's weight and nutrition. For example, one teacher said,

She was bigger size and I think teased, she was teased. So for that reason when I met [inaudible] and I mentioned that I said you know I think we could do something about her diet and they took it on. And she was meeting with them on a regular basis and she was bringing all of the feedback back to me about what she is eating now and how she is exercising. She is now in grade six. She looks fabulous. She continues to exercise and pay attention to what she is eating.

Across all stakeholder groups, there was an agreement that the provision of physical health care was very important. Children also indicated that, "Everyone goes there [SBHC] on a snow date and they get injected" and that the SBHC treated their frostbite.

\section{b) Mental health services at the school-based health clinic.}

Teachers and parents expressed converging perceptions about the need for greater mental health support services of the SBHC. Approximately half of the parents talked about the need for mental health services. For example, one parent expressed the need for an on-site psychologist because the children belonged to a high priority community and shared the following: 
But you know when children have issues, child psychologists will help. Sometimes it's just having that person there to give the assessment and do the recommendation for testing being done. You know coming here and asking for a doctor or a nurse practitioner, they can share things, they can refer, you can go someplace else, but there is a high need within the school.

The parents expressed the need for increased awareness to reduce the stigma around mental health,

for instance one parent said,

Whenever it comes to mental health issues it's threatening... You have somebody in the school who is working with these children, he is opening up that - they actually are normal... They need someone to put them in some kind of direction. So when you have a high need or a high-risk school it's beneficial.

Confidentiality about their children's mental health was also important to parents. For example, one parent said,

I don't think it's the principal and the vice principal's job or the teachers job - okay they are involved, but see if I want to take my son to a therapist or a psychologist about something why do I have to let them know?

Teachers similarly expressed that parents have confidentiality concerns, for instance, one teacher said, "We have grade ones telling us, 'I'm not allowed to talk about it' if something happens at home. Their parents have warned them." When teachers spoke about the need for greater mental health support services for families, they discussed the higher prevalence of community violence the children witness. For example, one teacher said,

We have had complete real lock-downs here because of a shooting in the neighbourhood which affects you know the kids. Kids will come to school sometimes talking about a stabbing... so kids come with that information and dealing with it.

Another teacher said, "They come to school and they fall asleep at 9am in the morning. There are huge issues with the mental health with the home life that the clinic and us we can't help with." Another teacher expressed, "Parents could have mental health issues but it's teaching the parents how to properly parent...Along with mental health is substance abuse."

The teachers spoke about the children's behavioural problems as well and one teacher said, "In a special education self-contained classes sometimes you get very aggressive children that can 
hurt another child...take a child for example that's been scratched in the face." Another teacher was shared the following:

We talk among people who work in other schools sometimes. We will talk about a kid with behaviour issues in their class. 'I've got the most challenging kid in the school' and you're thinking in my class that's like number four.

Teachers expressed that children experienced challenges related to anger, abuse, anxiety, major depression and frustration in children as young as four years of age. One teacher said, "In the area of mental health, children's mental health, for me, no. I wish. We have a huge need for more attention to that," and one teacher said it would be the "dream direction to go in" for the SBHC.

\section{c) Enhanced coordination of services.}

The enhanced coordination of services was important to both parents and teachers. For example, one parent said the following:

They could start a process of identifying what that problem could be. And that was beneficial. Also it was beneficial more so because the parent and family literacy center, the daycare, the teachers, everybody had input. It wasn't a clinic isolated from the community, it's inside the community.

Many parents said they learnt of the SBHC services through recommendations from the Parent and

Family Literacy Centre (PFLC) offered by the school. Another parent reported the SBHC was a great resource for parents looking for direction. For example, one parent said,

You know it was a difficult time to be going in and talking about everything with the doctor, but she was patient and gave me a lot of information and started a process that would allow us to focus on what could be a problem.

Teachers discussed the importance of their collaborative team meetings that takes place between classroom teachers, speech therapist, vice principal, and school support team. However, a teacher expressed the need for more opportunities to conduct team meetings and shared the following:

Well the problem is we've got 750 kids and we have one afternoon a month to get to all of the kids so you may be waiting six months to have meeting, so that's one of our concerns that we don't have enough time to get the kids through. 
The SBHC provided enhanced coordination of services, however, limited opportunities for team meetings was a challenge in meeting the needs of the community.

\section{Question two: What are children's, parents' and teachers' perceptions of their access to the school-based health clinic?}

Children, parents, and teachers were asked about their perceptions of the SBHC's accessibility. Parents and teachers shared converging perceptions about barriers related to the Ontario Health Insurance Plan-related (OHIP) and the need for culturally sensitive health care. Children, parents, teachers discussed the need for more days of operation. The following themes emerged from the data: (a) OHIP-related barriers to accessibility; and (b) hours of service and accessing information at SBHC.

\section{a) OHIP-related barriers to accessibility.}

The capacity of the SBHC to address OHIP-related barriers was particularly important to parents and teachers. The SBHC provided immediate health care for families who lacked OHIP coverage, which was particularly important for recent immigrants and refugee claimants. For example, one parent who was a newcomer said the following:

It's been a year later and I am still waiting. You call and they say 'oh we haven't got to your application yet. We have it but we haven't gotten to it. So then what do I tell my son if I should get sick or myself or whoever in my family?

One parent shared the difficulties of lacking health insurance and said, "It was closed so I tried to take her to the nearest walk-in clinic but they said she doesn't have any medical coverage and they couldn't see her. So I was forced to treat her at home." When the walk-in clinics were closed, the parents had to take their child to the emergency department. For example, one parent said, "Without the health card, the first thing they ask you is 'okay you have to pay for registration' [at the emergency department] and it's \$600." The SBHC addressed OHIP-related barriers, and a parent 
said, "like a blessing for the parents especially for those of us who don't have a health card...It gives equal access for all. So I think this is the best part of the school."

Teachers shared similar concerns about the adverse effects of health care inaccessibility and the inability of families to afford out-of-pocket physician and hospital fees. One teacher expressed, “...they couldn't take her to the doctor. They were giving antibiotics from a family member. Like they are medicating her themselves. Because they had no choice." The teachers empathized that parents must "feel kind of helpless" and recounted scenarios in which several families had been deported. Teachers discussed the greater number of refugee claimants at the school and the importance of timely medical help because "the sooner you get to some problems, the less expensive they become." While the SBHC provided health care services for uninsured children and families living within the catchment area, the limited hours of operation made accessing the services challenging.

\section{b) Hours of service and accessing information at school-based health clinic.}

When describing the hours of operation and services of the SBHC, the parents mentioned that the "only bad" aspect was "they are just open for one day" and "it's just opened Thursday and that's it". For uninsured families, the SBHC is their primary source of health care. Other parents discussed the need for a quiet space at the SBHC during the week. For example, one parent said,

I agree with her it should be open more often because my daughter she goes to the office because she is sick all the time and normally she just needs somewhere to - like a quiet space. It's only open Thursday and the only place she can go in is the office and it makes [her] feel ashamed sitting in the office...I used to take her home just over a headache... So I would rather [her] have a place where she can sit down and relax. It would be better if it was open. Even if the doctor is not there, just be open so she can sit there and relax.

Children had converging perceptions with parents and one child said, "What if you break your arm or hurt yourself on a Monday, the clinic should be open." [2011]. Another child said, "They should open the doors in the summer time, if get hurt in the summer time, I don't want to walk all the way to my doctor's office - if I can just come here" [2012]. 
In addition, both teachers and children discussed the importance of making information about the SBHC more accessible. Teachers shared "formal" information in the form of "pamphlets with information" and "a handout" would be helpful. For example, one teacher said,

Being a new person as well, before I got hired here I went on the school website to learn more about the school and that's where I saw that... Reading it online I thought maybe it was a nurse's office or a proper office the clinic runs out of. I had no idea.

Another teacher shared, "I would have loved to [refer students] but because of the lack of information I wasn't sure how the procedure works and how the referral works." The importance of making information more readily available was important to the children as well. For example, one student said,

But it's never been announced on the announcements or anything so I can't ask to go down the clinic just to sit there for a couple of minutes because I don't know if I am allowed to. They don't really talk about it so I don't know [2012].

Another child said, "I think they should have an open sign even if they don't use announcements" [2011]. Whereas the SBHC provided health care services to families and children, participants shared about the limited SBHC information which made accessibility challenging.

\section{Question two, part (b): Are there changes in children's perceptions of their access to the school- based health clinic over time?}

Children's perceptions of the accessibility of the SBHC changed over time based on a comparison of the perceptions from 2011, 2012 and 2015. During the early implementation of the SBHC, a child said they believed the funding that went into the SBHC was withdrawn from other activities. One child, who explicitly made this connection said, "They could have made a cricket team, they were going to make a soccer field and all that... There was supposed to be a la cross team, but they spended [spent] all their money on the clinic" [2011]. Children perceived that the SBHC was closed more frequently in 2011 and said, "I think they should have an open sign even if they don't use the announcements. If you are walking down the hall, and you want to go to the clinic, you know 
that you can." Another child said, "The clinic, it made me and my friends really mad about it." [2011].

In 2012, the lack of accessibility of the SBHC was reiterated by another child who said, "To me the clinic is like the clinic is like the school hospital - if the hospital is open all the time, the clinic should be open all the time as well.” [2012]. Children said the SBHC was not accessible because it "was not open to us" [2012] and another child said, "I don't feel like anybody is going to the clinic." [2012].

In 2015, there was a change in children's perceptions of the accessibility of the SBHC, in comparison to the earlier phases of implementation in 2011 and 2012. One child said, "I was actually [there] two times. This was in here too. I have to check my whole body. A specialist came in and they had to check my whole body" [2015]. Another child said, "I got scraped on my knee and they gave me ice and a Band-Aid" [2015]. When asked about their experiences at the SBHC, other children said they received flu shots and were familiar with the location of the SBHC. In 2015, many children had used the SBHC between one and five times. Additionally, in comparison to 2011 and 2012, there was an absence of the children's critique of the SBHC in 2015.

\section{Question three: What are children's, parents' and teachers' experiences of comfort (or discomfort) in accessing the school-based health clinic?}

Children, parents, and teachers expressed converging perceptions regarding their level of comfort in accessing the SBHC. Children described their perceptions of comfort in accessing the SBHC, and parents discussed their perceptions ofthe children's level of comfort. Teachers and parents had converging perspectives about the responsive SBHC staff. The findings comprised of the following themes: (a) accessibility related to the sense of community at school; and (b) accessibility related to the SBHC staff. 


\section{a) Comfort related to the sense of community.}

The parents shared that the SBHC was a part of the community at the school and said that this added to the comfort level of the children who used the services. One parent said the SBHC was, "more relaxing" and another parent said that, "the school is safe connection." In reference to the SBHC, another parent said, "Here it is more cozy for my son. It feels like home, it just feels like home here." The SBHC was described as part of the "village" at the school. For example, one parent said,

It's not just about convenience. It's a part of the school. You know like everybody has said their children feel comfortable coming because it's a part of the school. It's like this school has become a village itself... Then when you have a village they get to know each other. You bump into people in the clinic all the time. So it's more than convenience, it's just a part of building a community.

Parents also discussed the importance of the school location because the SBHC was located near classrooms and utilized by classmates. For example, one parent said,

A lot of them, their children have been at my home that type of thing. You know that when children recognize people and they see them all the time they become secure. When it's different people going to different places it is unsettling for them.

Another parent said of the school location, "I think that it's in the school that my daughter thinks it's just part of the school...If the other kids are doing it, she is only four so she just assumes its part of the school too." A parent expressed that having fewer adults in the waiting room made the SBHC a more child-friendly environment. For example, for instance, one parent said, "The main thing is that the children feel comfortable there. Because in other clinics they need to just sit like the adult people but here the environment is better." The sense of community that the SBHC was a part of was tremendously important and according to parents, the SBHC was "a part of the school" and this reduced children's stress because the "children really need that routine." 


\section{b) Comfort related to the school-based health clinic staff.}

Children, parents, and teachers expressed converging perceptions of the importance of the SBHC staff. For example, a child said that although he did not remember their names, and "only their faces," he expressed, "the people are nice." In addition to "giving treats" and stickers to children during immunization appointments, the SBHC staff provided toys to the children.

Parents described the personal attention and caring of the SBHC staff. For example, one parent described the SBHC nurse as "remarkable." Another parent compared the personal attention at the SBHC with the impersonal nature of walk-in clinics and shared the following:

If they don't read the file they don't know what's going on. So that's my problem I was having with the walk-in clinic. We come in here with [nurse practitioner] and she says, "Oh hi I just saw you last month. How are you?" She actually knows what's going on because she knows her patients. So that was quite the difference.

Another parent shared of the nurse practitioner, "She is very calm. She is very inviting and she is calm. She becomes friends and they are not upright like the other doctors at other clinics." A parent, who said her child was very afraid of needles said, "She was patient. She just waited and waited and said she didn't care if it took like three hours but she was going to give him that needle." The parents said the SBHC staff "tries to make it fun for the kids" and they "go the extra mile" to help the families obtain information that they need. For example, one parent said,

And if they get the support from the school it is a big help. So that time I don't know anybody. I don't know my neighbour. I'm very new here. When I take my child to school there is a settlement worker, there is a clinic, it is a good place, how can I get help you. I need these things. He goes he gave information to me, healthcare information, settlement information and it is free.

One teacher said, "The clinic coordinator is fabulous. Very flexible, gets back to you right away and is very helpful to families." The stakeholders across all groups described the importance of the SBHC and their positive perceptions of the SBHC staff. For example, one teacher said,

He actually came and met us to walk the family to the clinic to then talk to them to make sure that they were able to understand because English is not their first language. It was fantastic because he was making sure that they would get to see them so he could give them the information and all of that. 


\section{Question three, part (b): Are there changes in children's perceptions of the school-based health}

clinic as a comfortable (or uncomfortable) place over time?

Child perceptions of the SBHC as a comfortable place were relatively stable across the 2011, 2012 and 2015 cohorts. For example, one child shared, "you can be comfortable there because it is quiet, not too loud" [2012]. Another child said, "It's also a comfortable place because when times when we have classic drumming thing I didn't have my work finished and I asked Mr. M if I could finish my work at the clinic instead." [2012]. When sharing about favourite programs during the school day, one child said, "the clinic is definitely one" [2011].

Children perceived the SBHC as a comfortable place. In 2012, one child said, "It's really comfortable because sometimes when I pray - one prayer it starts at 2:15 and that's when recess is so I go down to the clinic and pray there." The children said they recognized the SBHC staff members' faces and said, "the people are nice" [2015]. Another child said it was comfortable "Because when you get hurt they will make you feel better" [2015]. In 2015, children similarly discussed the comfort of the SBHC and a child said, "they give you a treat" [2015] and "they gives us lollipop" [2015] and "one man uses the computer and the other girl gives you needles" [2015]. The children perceived the SBHC as a comfortable place over time from 2011, 2012, and 2015.

\section{Summary of Findings}

The findings from this study demonstrate that the SBHC plays a key role in the provision of health care for children and reduced health-related school absences; however, the absence of an onsite mental health practitioner was identified as a critical gap in services by parents and teachers who identified the community as a high-priority school. While parents expressed concerns regarding confidentiality, stigma and the lack of community awareness of mental health challenges, teachers expressed concerns regarding the difficult circumstances at home that some children experienced. 
OHIP-related barriers addressed by the SBHC were tremendously important and for particular for parents who were newcomers and lacked access to a regular primary health care provider. The enhanced coordination of services and the collaborative approach of SBHC health providers, school staff, and parents were important; however, the limited hours of service impeded the accessibility of the SBHC.

Across all three stakeholder groups, children, parents, and teachers expressed that the SBHC staff were helpful in ensuring families' received necessary health care services and settlement information. Converging evidence from parent perceptions and children's experiences of comfort over time, demonstrated that the SBHC was a comfortable place and recognized as part of the community. Children's perceptions of the accessibility of the SBHC also changed analogous to the increased utilization and knowledge of the SBHC. The following chapter discusses the results of the present study, including child, parent and teacher perceptions of the role of a SBHC in health care, perceptions of accessibility and comfort, along with changes in children's perceptions over time. 


\section{CHAPTER IV}

\section{Discussion}

This chapter will provide a greater in-depth exploration of the findings including child, parent and teacher perceptions of the role of a SBHC in health care, perceptions of accessibility and comfort, along with changes in children's perceptions over time. The findings in this study are discussed in connection to the literature, limitations of the study are identified, and the implications of the findings for future research are discussed.

\section{Question one: What are children's, parents' and teachers' perceptions of the role of the school- based health clinic in providing health care?}

\section{a) Physical health services and reduced health-related school absences.}

Children, parents, and teachers had converging perceptions of the provision of SBHC physical health services, and made specific mention of the importance of school immunizations. School-located immunizations were of particular importance for teachers who said it increased opportunities for children to stay in school and reduce school absences. The American and Canadian literature report similar findings, where in one study, 85.2\% of American students were able to return to class (Wade et al., 2008) and in another, $99.2 \%$ of Canadian students returned to class after a SBHC visit (Freeman et al., 2013). This is particularly important in the province of Ontario, Canada because the Immunization of School Pupils Act (1990) requires that all children attending schools in Ontario be immunized against: diphtheria, tetanus, polio, measles, mumps and rubella (Ministry of Health and Long-Term Care, 2015). Children with an incomplete immunization record will be suspended until complete records are provided to Toronto Public Health (Ministry of Health and Long-Term Care, 2015). The parents made specific connections between the SBHC physical health services and children's increased opportunities to learn in school. Prior studies indicate that the 
SBHCs were essential in improving children's timely access to care because parents may not be able to take time off work for medical appointments located elsewhere (Wade et al., 2008). The provision of vaccinations represented an important source of preventative care for parents. This is supported by the literature that found that vaccinations accounted for nearly half (47\%) of all SBHC visits between 2010 - 2011 (Yau \& Newton, 2012).

The parents' and teachers' explicit mention of the nutritional information provided at the SBHC, in addition to the mention of immunizations and SBHC's referral services demonstrate that the SBHC is an important first point of contact for children and families. The scope of services offered at the SBHC are comparable to the services offered in the American SBHCs (e.g., health care maintenance evaluations, immunizations, screening tests, first aid, diagnostic, acute care, and referrals) (Baquiran et al, 2002; Wade et al, 2008), which demonstrate a strong emphasis on the provision of primary health care services. Primary health care encompasses a broad range of services that include health promotion, disease prevention, referral services in addition to basic emergency care (Yau \& Newton, 2012). The perceptions of children, parents, and teachers showed that the SBHC has an important role in the provision of physical health services and the reduction of healthrelated absences.

\section{b) Mental health services at the school-based health clinic.}

A salient theme that emerged from the data were parents' and teachers' converging perceptions about the greater need for mental health support at the SBHC. Parents indicated that their children experienced a great amount of stress, while teachers indicated that the children were often witness to community violence and other difficult circumstances at home which impacted their mental health. The research literature supports that schools are in key locations to provide overall mental health promotion, community awareness, and coordinated mental health services (Brown \& Bolen, 2008). Parents explicitly mentioned the opportunities afforded at the school to increase 
community awareness surrounding mental illness because of the existing stigma that they perceive amongst the community. Stigma refers to experiences or witnessing statements or depictions of attitudes that degrade or devalue an individual due to a personal characteristic (Wahl, 2012). Parents explicitly mentioned the threatening nature of mental illness and the benefits of an on-site mental health service. Trivette and Thompson-Drew's (2003) research found that the incorporation of on-site mental health services at a school provides additional contextual information in terms of children's past social or educational records, prior mental health evaluations, and administrative support that can significantly enhance the provision of mental health service, support, and treatment.

Teachers in this study discussed the behavioural and mental health challenges that their students experience and made explicit connection to the impact this has on their educational attainment. A Canadian study that investigated the behavioural challenges of children in inner city schools, similarly reported incidents of aggressive behaviour, academic disengagement (e.g., time management and completing academic responsibilities), verbal and behavioural challenges (e.g., tantrums, swearing, screaming, and hitting), amongst other non-compliant behaviours with their peers that frequently affected classroom learning (McCready \& Soloway, 2010). While parents spoke about the importance of mental health services in school, teachers also alluded to the sense of distrust that some parents had toward sharing about home difficulties with educators and school administrators. The socio-demographic composition of the school, in addition to the information provided by the teachers throughout the focus group indicated that some families at the school were refugees or refugee claimants. Studies that investigate the experiences of refugee families and children arriving to Canada show that the process of seeking asylum is frequently associated with a high degree of fear of persecution in the home country and fear of deportation in the new country (e.g., Chuimento et al., 2011). The fear of deportation due to various immigration, judicial, and administrative reasons may affect parents' and families' sense of safety in disclosing personal or familial information with teachers and school administrative staff. This theme that emerged from the 
data offers implications for practice. Based on this study, it seems that additional mental health services at the case study site would be helpful. Furthermore, based on the research, parents may require additional reassurance relating to the confidentiality of their health care information and the information that they disclose in the SBHC.

\section{c) Enhanced coordination of services.}

The enhanced coordination of services between educators, parents, and health professionals at the SBHC was particularly important to parents, while teachers valued the collaboration and teamorientation of the SBHC care. The literature on the nurse practitioner model of care delivery in SBHCs is characterized by a "team" orientation that includes sensitizing school staff to the potential learning barriers that their students face, and meeting with families to understand their needs and priorities (Yau \& Newton, 2012). This provides opportunities to enhance assessment and treatment that can be tailored to children's needs and facilitate improved educational outcomes (e.g., StrolinGoltzman et al., 2014; Trivette \& Thompson-Drew, 2003). While the literature on SBHCs underscores the enhanced coordination of care with external community or medical primary care physicians (Johnson \& Hutcherson, 2006), the parents in this study alluded to the importance of the coordinated care that occurs within the school community. Fostering an environment of improved communication pathways between the home and school can increase the parent-provider conversations that benefit children's health (Peacock \& Lin, 2012).For example, the coordination of

care can significantly improve the early detection of autistic spectrum disorder (ASD) where children can show inconsistent signs (Peacock \& Lin, 2012). An integral part of the roles and responsibilities of SBHC staff is to consult with families, community agencies, and school administrative staff (Mavis, Pearson, Stewart, \& Keefe, 2009) which can improve treatment plans and assessment (e.g., Yau \& Newton, 2013). In line with the ecological systems theory (e.g., Bronfenbrenner, 1979; 1986), 
these connections across the microsystems of home, school, and community health services, represent mesosystem influences on children's development.

\section{Question two: What are children's, parents' and teachers' perceptions of their access to the school-based health clinic?}

\section{a) OHIP-related barriers to accessibility.}

While Ontario has one of the largest publicly funded health care systems in the world (Health Canada, 2014); a proportion of individuals still experience persistent challenges obtaining needed health care. The findings in this study show that an individual's capacity to attain necessary health care can be challenged by immigration status and complex factors that restrict accessibility to health care. Further, the findings contextualize important aspects of accessibility and reveal that beyond factors related to geographical proximity and the convenience of medical appointments (Asanin \& Wilson, 2008), parents' accessibility was largely influenced by OHIP-related barriers. The lack of health insurance in Canada is frequently related to the three-month waiting period for newcomers (Ontario Medical Review, 2011). And individuals in Canada who are seeking asylum are not entitled to OHIP coverage (Ontario Health Insurance Act, 1990); however some refugee claimants are eligible for the Ontario Temporary Health Program recently implemented to address health care gaps (Ministry of Health and Long-Term Care, 2013). A recent Canadian study illustrated that healthcare seeking behaviour was impeded for those without health insurance due to complicated barriers related to discrimination, fear of deportation, language barriers, and immigration status even though they may be experiencing challenges affecting their health (Campbell, Hodges, Fisman, \& Kitto, 2014). The study reported that emergency care was only sought when the medical condition was so severe that they feared for their lives, otherwise over-the-counter medications were purchased to ease symptoms (Campbell, Hodges, Fisman, \& Kitto, 2014). School-based health clinics represent an 
important response to helping children and families in this study who are in the process of receiving health insurance, lacked the means to afford out-of-pocket medical expenses, or faced other barriers.

The literature in the United States shows evidence that SBHCs frequently serve families who reported facing substantial barriers related to health insurance coverage and economic barriers (Baquiran et al., 2002; Carpenter \& Mueller, 2001; Wade et al., 2008). The parents in this study who tried to obtain other medical services at hospitals or walk-in clinics, sometimes had health care withheld because of one's inability to pay for medical care due to financial charges in the absence of insurance. For parents, the regulations (e.g., minimum three-month residency requirement or lack of OHIP) were identified as prominent barriers to obtaining health care in Canada. Similarly, American literature also shows the capacity of SBHCs to address insurance-related barriers to health care access (e.g., Baquiran et al., 2002; Wade et al., 2008). While the contexts differ, SBHCs in Canada support the aims of creating accessible and universal health care, principles outlined by the Canada Health Act of 1984 that include the provision of medically needed services are provided on the basis of need and not on the basis of an individual's ability to pay (Madore \& Tiedemann, 2005). This study has policy implications for the health care eligibility of individuals who are newcomers to Canada.

\section{b) Hours of service and accessing information about the school-based health clinic.}

While parents and children discussed the importance of having greater days of service at the SBHC, teachers expressed the importance of having more "formal" information about the SBHC. In the U.S., some SBHCs are open every day throughout the school year (Baquiran et al., 2002); however school vacation periods and holidays were reported to be a barrier to utilization (Carpenter \& Mueller, 2001). Parents in the current study reported that the hours of operation limited to one day impeded the accessibility of the SBHC services. The parents shared the benefits of expanding operating hours during the daytime which they felt would help children who required a "quiet space" 
or children who experience headaches and stomach aches that may have stemmed from being overwhelmed in the classroom. It can be alluded from the parent focus groups, that accessibility might be significantly improved if there were even another day of service. However, it is important to note that underlying the discussion was a sense of parents' gratitude for the SBHC's services.

For teachers, improving access to information about the SBHC was important. Teachers expressed that greater access to information would allow them to refer more students to the SBHC. The literature shows that teachers are in excellent positions to identify problems early on because they interact and see students on a daily basis, and are often the main point of SBHC referrals, with parent referrals increasing over time (Wade et al., 2008).. This suggests that providing more information and brochures to teachers is important because they may frequently be the first-point of contact between SBHCs and families. Furthermore, expanding the hours of operation of the SBHC may help reach more families and improve accessibility.

\section{Question two, part (b): Are there changes in children's perceptions about their access to the school-based health clinic over time?}

Children's perceptions of accessibility to the SBHC changed over time from 2011, 2012, and 2015. In 2015, the majority of children perceived the SBHC as an accessible and familiar place; however during the early implementation of the SBHC in 2011 and 2012, more children perceived the SBHC as inaccessible. One can speculate from the research literature investigating children's perceptions and experiences of health care, that perhaps greater opportunity to participate in the decision making processes and improved access to information about the SBHC would be beneficial for students. For instance, one child in early implementation speculated that the school's investment into the SBHC negatively impacted the quality of other school programs (e.g., la cross team and a dance party). In another study investigating children's experiences of health care services, reported that children have a desire to be involved in decision making processes on matters that affect them 
(Coyne \& Gallagher, 2010). Another study showed that children as young as 7 years of age demonstrated that they valued being listened to and an understanding of when their preferences for health care have been ignored (Bone, O’Reilly, Karim, \& Vostanis, 2014). The current study in connection with the literature suggests that children at the focal school may have perceived their voices and interests to be excluded from the dialogue in the early implementation of the SBHC. The findings highlight the importance of including children's voices in research and practice.

Over time, however, children perceived the SBHC as a more accessible place, and this finding aligns with reports of increased utilization of the SBHC. For example, a TDSB report showed that there was an increase in student appointments from 283 appointments in 2011 to 1,227 appointments in 2013, representing a four-fold increase over time (Yau \& Newton, 2013). In addition, the positive changes in children's perceptions of accessibility may reflect their growing recognition of the SBHC as an important aspect of their school community, and reflects the support of the SBHC by their families and teachers. The changes in children's perceptions of accessibility over time may be related to the contextual differences in 2011 during its early phase of implementation of the SBHC and improved operations and programming in 2015 due to its lengthier period of establishment.

\section{Question three: What are children's, parents' and teachers' experiences of comfort (or discomfort) in accessing the school-based health clinic?}

\section{a) Comfort related to the sense of community and SBHC staff.}

Parents shared that the SBHC was a part of their school community and a comfortable place for children to utilize services within a caring school community. These findings suggest that feelings of belonging in the school community may have influenced parents' decision to utilize the health services. Furthermore, the sense of belonging in the community may be particularly important for newcomer families who may be experiencing isolation and challenges associated with acculturating 
to a new country (Hurtado-de-Mensoza, Gonzales, Serrano, \& Kaltman, 2014; Schwartz, Unger, Zamboanga, \& Szapocznik, 2010).

The parents and teachers in this study also highlighted the importance of the SBHC staff in parents' perceptions of the SBHC as a particularly comfortable place. While the MSPHI SBHC predominately uses a nurse practitioner's model of care delivery (Strozer et al., 2010; Yau \& Newton, 2012), the SBHC also employs a clinic coordinator who has an important role in the facilitation of community awareness, consulting with school personnel, and meeting with families to understand their needs and priorities (Yau \& Newton, 2012). The literature shows that the nurse practitioner philosophy of patient-care indicates a caring-orientation, in terms of the amount of time spent listening to clients' concerns and past history, and providing greater continuity of care (e.g., seeing the same patient at each appointment) (Gambino, Planavsky, \& Gaudette, 2009; Gould et al., 2007). Additional evidence in the literature show that SBHC staff (e.g., nurse practitioners, paediatricians, and counsellors) are in key positions to facilitate positive and supportive relationships with students to enhance assessment and treatment that can improve educational outcomes and reduce student risk behaviours (Strolin-Goltzman, Sisselman, Melekis, \& Auerbach, 2014). The parents' and teachers' discussions of the SBHC staff as having a caring approach to service suggests that the SBHC staff are able to provide tailor services to the unique needs of the families and communities.

\section{Question three, part (b): Are there changes in children's perceptions of the school-based health clinic as a comfortable (or uncomfortable) place over time?}

Children's perceptions of the SBHC as a comfortable place remained relatively stable over time based on the focus group data in 2011, 2012, and 2015. The unique location of the SBHC in an elementary school where it is located close to school peers and teachers distinguishes it from a physician's medical clinic that may be an uncomfortable place for some children. Parents' offered 
insights into the children's perceptions of comfort at the SBHC. Parents stated the environment at the school was child friendly and as a result, it was a more relaxing and pleasant atmosphere. In addition, the availability of toys in the waiting area was important to children's perceptions of the SBHC as a comfortable place. The SBHC is perceived as a child-friendly setting and this is substantiated by a study that investigated children's experiences of accessing hospital services, where children reported a significantly higher preference for a child-friendly waiting area that had activity books, magazines, picture books, and toys that were age-appropriate (Curtis, Liabo, Roberts, \& Barker, 2004).

\section{Limitations of the Study}

This qualitative study used convenience sampling, due to the fact that children, parents, and teachers volunteered to participate in the study, and as such, there may be a selection bias. Therefore, this convenience sample may not be representative of the perceptions and experiences of all children, parents, and teachers at the focal inner city Toronto school or all users of the MSPHI SBHCs in Canada. However, the sociodemographic composition of the parents, suggests that the sample was generally comparable to the socio-demographical composition of families delineated in the MSPHI and TDSB reports (e.g., Yau \& Newton, 2012; Yau \& Newton, 2013).

Another limitation of the research study had to do with the qualitative focus groups carried out over time. The comparisons over time did not sample from the same groups of children and involved cohort comparisons. As such findings relating to changes over time may have been influenced by other factors unknown to the researchers. It is noteworthy that at times, the conversations among participants veered into different topics; however, the discussions provided insight into the personal challenges related to health care access that may not have otherwise been revealed. While the results of the present study cannot be generalized to large populations, the findings can be applied to similar contexts and populations (Shenton, 2004). For instance, the findings from this study could be used to inform future studies investigating SBHCs in Canada. 


\section{Conclusion}

The MSPHI SBHC aims to remove health care barriers related to four key areas: the lack of OHIP insurance, lack of primary health care practitioners, financial difficulties parents' faced with paying the cost of transportation and doctor's appointments, and language barriers to accessing health care (Yau \& Newton, 2012). The findings in this study demonstrate that the MSPHI SBHC is able to meet its goals of reducing these health care barriers, particularly for newcomer and refugee populations. The purpose of this study was to qualitatively investigate the perceptions and experiences of children, parents, and teachers at a MSPHI SBHC. Parents in this study reported facing a variety of complex barriers to health care access and described the role of the SBHC in their health care. The findings from this study, although preliminary in nature, suggest that the provision of primary health care for families reduced health-related school absences. While there was a need for greater mental health services; the caring SBHC staff along with the school's sense of community, contributed to parents' positive perceptions of the SBHC. In addition, the enhanced coordination of care between educators, and health providers created a supportive network that assisted families in accessing services in support of their children's health. Children perceived the SBHC as a comfortable place and their perceptions of accessibility improved in conjunction with the increased utilization of the SBHC over time. The MSPHI SBHC model, including its approach to health care, caring staff personnel, and innovative school location makes it an accessible and comfortable setting for families to obtain primary health care. While there is literature in the United States that investigates children's utilization and accessibility of SBHCs (e.g., Baquiran et al., 2002; Carpenter \& Mueller, 2001; Johnson \& Hutcherson, 2006), there is limited research investigating SBHCs in a Canadian context. The present study will yield insights relevant to the future implementation of similar SBHC models in Canada. Further, this study adds to the research literature by including children's perceptions and voices concerning their health and educational experiences. 
Finally, the research has implications for Canadian health care policy that affects marginalized families' eligibility for health insurance and access to health care. 


\section{References}

Allen, P. J., Meadows-Oliver, M., \& Ryan-Krause, P. (2008). Establishing a school-based clinic in Managua, Nicaragua. Primary Care Approaches, 34(3), 262-266.

Ali, M. M., Dwyer, D. S., Vanner, E. A., \& Lopez, A. (2010). Adolescent propensity to engage in health risky behaviors: The role of individual resilience. International Journal of Environmental Research and Public Health, 7(5), 2161-2176.

Atkins, M. S., Hoagwood, K. E., Kutash, K., \& Seidman, E. (2010). Toward the integration of education and mental health in schools. Administration and Policy in Mental Health, 37(1-2), 40-47.

Asanin, J. \& Wilson, K. (2008). "I spent nine years looking for a doctor": Exploring access to health care among immigrants in Mississauga, Ontario, Canada. The Social Science \& Medicine Journal, 66, 1271-1283.

Brindis, C. D., Klein, J., Schlitt, J., Santelli, J., Juszczak, L., \& Nystrom, R. J. (2003). School-based health centers: Accessibility and accountability. Journal of Adolescent Health, 32, 98-107.

Baquiran, R. S., Webber, M. P., \& Appel, D. K. (2002). Comparing frequent and average users of elementary school-based health centers in the Bronx, New York City. The Journal of School Health, 72(4), 133-137.

Berti, L. C., Zylbert, S., \& Rolnitzky, L. (2001). Comparison of health status of children using a school-based health center for comprehensive care. Journal of Pediatric Health Care, 15, 244-250.

Bone, C., O'Reilly, M., Karim, K., \& Vostanis, P. (2014). 'They're not witches...' Young children and their parents' perceptions and experiences of child and mental health services. Child: Care, Health and Development, 41(3), 450-458.

Braun, V. \& Clark, V. (2006). Using thematic analysis in psychology. Qualitative Research in Psychology, 3(2), 77-101. 
Bronfenbrenner, U. (1979). The ecology of human development: Experiments by nature and design. Cambridge, MA: Harvard University Press.

Bronfenbrenner, U. (1986). Ecology of the family as a context for human development: Research perspectives. Developmental Psychology, 22, 723-724.

Brown, M. B. \& Bolen, L. M. (2008). The school-based health center as a resource for prevention and health promotion. Psychology in the schools, 45(1), 28-38.

Canada Health Act, Revised Statutes of Canada (1985, c. C-6). Retrieved from the Department of Justice Canada website: http://canlii.ca/t/51w33

Cappella, E., Frazier, S. L., Atkins, M. S., Schoenwald, S. K., \& Glisson, C. (2008). Enhancing schools' capacity to support children in poverty: Ecological model of school-based mental health services. Administrative Policy: Mental Health, 3595, 395-409.

Campbell, R. M., Klei, A. G., Hodges, B. D., Fisman, D., \& Kitto, S. (2014). A comparison of health access between permanent residents, undocumented immigrants, and refugee claimants in Toronto, Canada. Journal of Minority Health, 16(165-176).

Canadian Institute for Health Information. 2010. Regulated Nurses: Canadian Trends, 2004 2008. Ottawa, ON: CIHI.

Carpenter, L. M., \& Mueller, C. S. (2001). Evaluating health care seeking behaviors of parents using a school-based health clinic. The Journal of School Health, 71(10), 497-499.

Caulford, P. \& D'Andrade, J. (2012). Health care for Canada's medically uninsured immigrants and refugees: Whose problem is it? Canadian Family Physician, 58(7), 725-727.

Citizenship and Immigration Canada (2011). Canada Facts and Figures: Immigration overview Permanent and Temporary Residents. Retrieved from the Government of Canada website: http://www.cic.gc.ca/english/pdf/research-stats/facts2011.pdf

Charmaz, K. (2006). Constructing grounded theory: A practical guide through qualitative analysis. Washington, DC: Sage Publications. 
Chuimento, A., Nelki, J., Dutton, C., \& Hughes, G. (2011). School-based mental health service for refugee and asylum seeking children: Multi-agency working, lessons for good practice. Journal of Public Mental Health, 10(3), 167-177.

Coyne, I. \& Gallagher, P. (2011). Participation in communication and decision-making: Children and young people's experiences in a hospital setting. Journal of Clinical Nursing, 20(15-16), 2334-2343.

Coyne, I. \& Harder, M. (2011). Children's participation in decision-making: Balancing protection with shared decision-making using a situational perspective. Journal of Child Health Care, 15(4), 312-319.

Corter, C., Bertrand, J., Pelletier, K., Griffin, T., McKay, D., Patel, S. \& Ioannone, P. (2007). Toronto First Duty phase 1 final report: Evidence-based understanding of integrated foundations for early childhood. Retrieved from: http://www.toronto.ca/firstduty/tfd_phase1_finalreport.pdf

Creswell, J.W. (2007). Qualitative inquiry and research design: Choosing among five approaches (2nd ed.). Thousand Oaks,. CA: Sage.

Currie, J. (2005). Health disparities and gaps in school readiness. The Future of Children, 15(1), 117-138.

Curtis, K., Liabo, K., Roberts, H., \& Barker, M. (2004). Consulted but not heard: A qualitative study of young people's view of their local health service. Health Expectations, 7, 149-156.

Crowe, S., Cresswell, K., Robertson, A., Huby, G., Avery, A., \& Sheikh, A. (2011). The case study approach. BMC Medical Research Methodology, 11(100), 1-9.

Daly, J. Z., Ziegler, R., \& Goldstein, D. J. (2004). Adolescent postabortion groups: Risk reduction in a school-based health clinic. Journal of Psychosocial Nursing and Mental Health, 42(10), 48 54. 
Dey, A. N., Schiller, J. S., \& Tai, D. A. (2002). Summary health statistics for U. S. children: National health interview survey. National Center for Health Statistics, 10(221).

Delafontaine, M., Neutens, T., Schwanen, T., \& de Weghe, N. V. (2011). The impact of opening hours on the equity of individual space-time accessibility. Computers, Environment and Urban Systems, 35(4), 276-288.

Donald, F., Martin-Misener, R., Bryant-Lukosius, D., Kilpatrick, K., Kaasalainen, S., Carter, N., Harbman, P., \& Bougeault, I., \& Dicenso, A. (2010). The primary health care nurse practitioner role in Canada. Advanced Practice Nursing, 23, 89-113.

Durbin, A., Moineddin, R., Lin, E., Steele, L. S., \& Glazier, R. H. (2015). Examining the relationship between neighbourhood deprivation and mental health service use of immigrants in Ontario, Canada: A cross-sectional study. BMJ Open, 5, 1-11.

Durlak, J. A., Weissberg, R. P., Dymnicki, A. B., Taylor, R. D., \& Schellinger, K. B. (2011). The impact of enhancing students' social and emotional learning: A meta-analysis of school based health universal interventions. Child Development, 82(1), 405-432.

Elgersma, S. (2008). Immigration status and legal entitlement to insured health services (Report No. PRB 08-28E). Retrieved from the Library of Parliament Website: http://www.parl.gc.ca/content/LOP/ResearchPublications/prb0828-e.htm

Fatemeh, R. (2004). Focus-group interview and data analysis. The Proceedings of the Nutrition Society, 63(4), 655-660.

Fernell, E., Eriksson, M. A., \& Gillberg, C. (2013). Early diagnosis of autism and impact on prognosis: A narrative review. Clinical Epidemiology, 5, 33-37.

Freeman, S., Sgro, M., Wormsbecker, A. E., Vandermorris, A. K., Thorpe, K. E., \& Mamdani, M. (2013). Feasibility study on the Model Schools Paediatric Health Initiative Pilot Project. Paediatrics \& Child Health, 18(7), 361-366. 
Fredheim, T., Danbolt, L. J., Haavet, O. R., Kjonsberg, K. \& Lien, L. (2011). Collaboration between general practitioners and mental health care professionals: A qualitative study. International Journal of Mental Health Systems, 5(13).

Gall, G., Pagano, M. E., Desmond, M. S., Perrin, J. M., \& Murphy, M. (2009). Utility of psychosocial screening at a school-based health center. Journal of School health, 70(7), 292 298.

Gambino KK, Planavsky L, Gaudette H. (2009). Transition toward a nurse practitioner-managed clinic. Journal of Cardiovascular Nursing. 24(2), 132-139.

Gampetro, P., Wojciechowski, E. A., \& Amer, K. S. (2012). Life concerns and perceptions of care in adolescents with mental care needs: A qualitative study in a school-based health clinic. Pediatric Nursing, 38(1), 23-30.

Geierstanger, S. P., Amaral, G., Mansour, M. \& Walters, S. R. (2004). School-based health centers and academic performance: Research, Challenges, and Recommendations. Journal of School Health, 74(9), 347-352.

Gould, O. D., Johnstone, D., \& Wasylkiw, L. (2007). Nurse practitioners in Canada: Beginnings, benefits, and barriers. Journal of the American Nurse Practitioners, 19, 165-171.

Government of Canada (2012). Refugees and asylum. Retrieved from the Government of Canada website: http://www.cic.gc.ca/ENGLISH/refugees/index.asp

Guo, J. J., Wade, T. J., \& Keller, K. N. (2008). Impact of school-based health centers on students with mental health problems. Public Health Reports, 123, 768-780.

Guo, J. J., Jang, R., Keller, K. N., McCracken, A. L., Pan, W., \& Cluxton, R. J. (2005). Impact of school-based health centers on children with asthma. Journal of Adolescent Health, 37, 266 274.

Health Canada (2012). Canada's Health Care System. Retrieved from the Health Canada website: http://www.hc-sc.gc.ca/hcs-sss/pubs/system-regime/2011-hcs-sss/index-eng.php 
Health Canada (2014). Canada Health Act Annual Report 2013-2014. Retrieved from the Health Canada website: http://www.hc-sc.gc.ca/hcs-sss/alt_formats/pdf/pubs/cha-ics/2014-cha-lcs ar-ra-eng.pdf

Hurtado-de-Mendoza, A., Gonzales, F. A., Serrano, A., \& Kaltman, S. (2014). Social isolation and perceived barriers to establishing social networks among Latina immigrants. American Journal of Community Psychology, 53, 73-82.

Immunization of School Pupils Act, Revised Statutes of Ontario. (1990, c. 1. 1). Retrieved from the Government of Ontario website: http://www.ontario.ca/laws/statute/90i01

Johnson, V., \& Hutcherson, V. (2006). A study of the utilization patterns of an elementary school based health clinic over a 5-year period. The Journal of School Health, 76(7), 373-8.

Katik, M., Budak, A., Ivankovic, D., Mastilica, M., Lazic, D., Babic-Baszak, A., \& Matkovic, V. (2001). Patients' view on the professional behaviour of family physicians. Family Practice, 18, 43-47.

Keeton, V., Soleimanpour, S., \& Brindis, C. D. (2012). School-based health centers in an era of health care reform: Building on history. Current Problems in Adoelscent Health Care, 42, 132-156.

Lincoln, YS. \& Guba, EG. (1985). Naturalistic Inquiry. Newbury Park, CA: Sage Publications. Long-Sutehall, T., Sque, M., \& Addington-Hall, J. (2010). Secondary analysis of qualitative data: A valuable method for exploring sensitive issues with an elusive population? Journal of Research in Nursing, 16(4), 335-344.

Kitchen, P., Williams, A., \& Chowhan, J. (2012). Sense of community belonging and health in Canada: A regional analysis. Social Indicators Research, 107(1), 103-126.

Lear, J. G. (2003). School-based health centers: A long road to travel. Archives of Pediatric Adolescent Medicine, 157, 118-119.

Link, B. G. \& Phelan, J. C. (2006). Stigma and its public health implications. The Lancet, 367, 
(9509), 528-529.

Lurie, N. Bauer, E. J., \& Brady, C. (2001). Asthma outcomes at an inner-city school-based health center. The Journal of School Health, 71(1), 9-16.

Madore, O. \& Tiedmann, M. (2005). Private health care funding and delivery under the Canada Health Care Act (Report No. PRB 05-052E). Retrieved from the Library of Parliament Website: http://www2.parl.gc.ca/Content/LOP/ResearchPublications/prb0552-e.htm

Mavis, B., Pearson, R., Stewart, G., \& Keefe, C. (2009). A work sampling study of provider activities in school-based health centers. Journal of School Health, 79(6), 262-268.

McCready, L. T., \& Soloway, G. B. (2010). Teachers' perceptions of challenging student behaviours in model inner city schools. Emotional and Behavioural Difficulties, 15(2), 111-123.

McNall, M. A., Lichty, L. F., Mavis, B. (2010). The impact of school-based health centers on the health outcomes of middle school and high school students. American Journal of Public Health, 100(9), 1604-1610.

Ministry of Health and Long-Term Care (2013). Ontario Temporary Health Program for the Refugee Claimants. Retrieved from the Ministry of Health and Long-Term Care website: http://www.health.gov.on.ca/en/pro/programs/othp/

Ministry of Health and Long-Term Care (2015). Immunization: School age children. Retrieved from the Ministry of Health and Long-Term Care website: http://www.health.gov.on.ca/en/public/programs/immunization/school_age.aspx

Offord, D. R., Kraemer, H. C., Kazdin, A. E., Jensen, P. S., Harrington, R., \& Gardner, J. S. (1999). Lowering the burden of suffering: Monitoring the benefits of clinical, targeted, and universal approaches. In D. P. Keating \& C. Hertzman (Eds.), Developmental health the wealth of nations: Social, biological and educational dynamics (pp. 293 - 310). New York: Guilford Press. 
Ontario Health Insurance Act, Revised Regulations of Ontario (1990, c. H. 6). Retrieved from the Government of Ontario website: http://www.ontario.ca/laws/regulation/900552\#BK2

Ontario Medical Review (2011). Reviewing the OHIP three-month wait: An unreasonable barrier to accessing health care. Ontario Medical Review, 13-18.

Padgett, D. K. (1998) Qualitative Methods in Social Work Research: Challenges and Rewards. Thousand Oaks, CA: Sage Publications.

Palley, H. A., Pomey, M., \& Forest, P. (2011). Examining private and public provision in Canada's provincial health care systems: Comparing Ontario and Quebect. International Political Science Review, 32(1), 79-94.

Patel, S. \& Corter, C. (2011). Early Intervention Research, Services, and Policies. In A. Slater, M. Lewis, G. Anzures, \& K. Lee (Eds.) Introduction to Infant Development, Canadian Edition. Toronto: Oxford University Press.

Patel, S., \& Corter, C. (2013). Building capacity for parent involvement through school-based preschool services. Early Child Development and Care, 183(7), 981-1004.

Patel, S., Corter, C., Pelletier, J., \& Bertrand, J. (2015). (2015). er, J., \& Bertrand, J.5, participation in integrated early childhood services and child outcomes: Ecological complexities. Manuscript submitted to Early Childhood Research Quarterly: Special Issue on international research utilizing the Early Development Instrument (EDI) as a measure of early childhood.

Peacock, G. \& Lin, S. C. (2012). Enhancing early identification and coordination of intervention services for young children with autism spectrum disorders: Report from the Act Early Regional Summit Project. Disability and Health Journal, 5, 55-59.

Ross, N. (2002). Community belonging and health. Health Reports, 13(3), 33-39. 
Schwartz, S. J., Unger, J. B., Zamboanga, B. L. \& Szapocznik, J. (2010). Rethinking the concept of acculturation: Implications for theory and research. American Journal of Psychology, 65(4), 237-251.

Scudder, L., Papa, P., \& Brey, L. C. (2007). School-based health centers: A model for improving the health of the nation's children. The Journal for Nurse Practitioners, 3(10), 713-720.

Shenton, A. K. (2004). Strategies for ensuring trustworthiness in qualitative research projects. Education for Information, 22, 63-75.

Stone, S., Whitaker, K, Anyon, Y. \& Shields, J. P. (2013). The relationship between use of school based health centers and student-reported school assets. Journal of Adolescent Health, 53, 526-532.

Stock, M. R., Morse, E. V., Simon, P. M., Zeanah, P. D., Pratt, J. M., \& Sterne, S. (1997). Barriers to school-based health care programs. Health \& Social Work, 22(4), 274-81.

Statistics Canada (2011). Table 202-0802. Persons in low income families. Retrieved from the Statistics Canada website: http://www5.statcan.gc.ca/cansim/a05?lang=eng\&id=2020802

Stone, S., Whitaker, K., Anyon, Y., \& Shields, J. P. (2013). Journal of Adolescent Health, 53, 526532.

Strolin-Goltzman, J., Sisselman, A., Melekis, K., \& Auerbach, C. (2014). Understanding the relationship between school-based health center use, school connection, and academic performance. Health Social Work, 39(2), 83-91.

Strozer, J., Juszczak, L., \& Ammerman, A. (2010). A 2007-2008 National School-Based Health Care Census. Washington, D.C.: National Assembly on School-Based Health Care.

Swick, K. J. \& Williams, R. D. (2006). An analysis of Bronfenbrenner's bio-ecological perspective for early childhood educators: Implications for working with families experiencing stress. Early Childhood Education Journal, 33(5), 371-378. 
Szumilas, M., Kutcher, S., LeBlanc, J. C., \& Langille, D. (2010). Use of school-based health centres for mental health support in Cape Breton, Nova Scotia.

The Toronto District School Board (2005). Model schools for inner city task force report. Retrieved from: http://www.tdsb.on.ca/Portals/0/Community/ModelSchools/InnerCityReportMay2005.pdf

The Toronto District School Board (2014). The 2014 Learning Opportunities Index: Questions and Answers. Retrieved from: http://www.tdsb.on.ca/Portals/0/AboutUs/Research/LOI2014.pdf

Townsend, N. \& Foster, C. (2011). Developing and applying a socio-ecological model to the promotion of healthy eating in the school. Public Health Nutrition, 16(6), 1101-1108.

Trivette, P. S. \& Thompson-Drew, C. (2003). Implementing a school-based health center: The Winston-Salem/Forsyth County experience. Psychology in Schools, 40(3), 289-296.

Van Soeren, M., Hurlock-Chorostecki, C., Goodwin, S., \& Baker, E. (2009). The primary healthcare nurse practitioner in Ontario: A workforce study. Nursing Leadership, 22(2), 58-72.

Vessey, J, and McGowan, K, (2006) A successful public health experiment: School nursing. Pediatric Nursing, 32(3) 255 - 256.

Walker, S. C., Kerns, S., Lyon, A. R., Bruns, E. J., \& Cosgrove, T. J. (2010). Impact of school-based health center use on academic outcomes. Journal of Adolescent Health, 46, 251-257.

Wade, T. J., Mansour, M. E., Line, K., Huentelman, T., \& Keller, K. (2008). Improvements in health related quality of life among school-based health center users in elementary and middle school. Ambulatory Pediatrics, 8, 241-249.

Webberm M. P., Carpiniello, K. E., Oruwariye, T., Lo, Y., Burton, W. B., \& Appel, D. K. (2003). Burden of asthma in inner-city elementary school children. Archives of Pediatric and Adolescent Medicine, 157, 125-129. 
Wenzel, M. (1996). A school-based clinic for elementary schools in Pheonix, Arizona. The Journal of School Health, 66(4), 125-127.

Whittemore, R., Chase, S. K., \& Mandle, C. L. (2001). Validity in qualitative research. Qualitative Health Research, 11(4), 522-537.

Yau, M. \& Branco, V. (2012). Achievement gap cannot be closed without first reducing the opportunity gap: A case study of Model Schools for Inner Cities. Retrieved from: http://www.tdsb.on.ca/Portals/0/Community/ModelSchools/2012_AERA_Paperon MSIC.pdf

Yau, M. \& De Jesus, S. (2014). Model Schools Paediatric Health Initiative: In-school health clinics. Phase 3 Report.

Yau, M. \& Newton, L. (2012). Model Schools Paediatric Health Initiative: In-school health clinics. Phase 1 report. Retrieved from http://www.tdsb.on.ca/Portals/0/Community/ ModelSchools/ModelSchoolsPaediatricHeathInitiativeInSchoolHealthClinicsPhase1. pdf

Yau, M. \& Newton, L. (2013). Model Schools Paediatric Health Initiative: In-school health clinics. Phase 2 Report. Retrieved from http://www.tdsb.on.ca/Portals/0/Community/ ModelSchools/ModelSchoolsPaediatricHeathInitiativeInSchoolHealthClinicsPhase2. pdf

Yau, M., Rosolen, L., \& Archer, B. (2013). 2011-2012 Student and parent census. Retrieved from: http://www.tdsb.on.ca/portals/Aboutus/Research/2011 12CensusfactSheet1Demophracs-17June2013.pdf

Zigler, E. F., Finn-Stevenson, M., \& Stern, B. M. (1997). Supporting children and families in the schools: The schools of the $21^{\text {st }}$ Century. American Journal of Orthopsychiatry, 67(3), 396-407. 